\title{
Noradrenergic $\alpha 1$-Adrenoceptor Actions in the Primate Dorsolateral Prefrontal Cortex
}

\author{
Dibyadeep Datta, ${ }^{1}$ Sheng-Tao Yang, ${ }^{1}$ Veronica C. Galvin, ${ }^{1}$ John Solder, ${ }^{1}$ Fei Luo, ${ }^{2}$-Y Yry M. Morozov, ${ }^{1}$ Jon Arellano, ${ }^{1}$ \\ ๑DAlvaro Duque, ${ }^{1}$ Pasko Rakic, ${ }^{1}{ }^{\circledR}$ Amy F.T. Arnsten, ${ }^{1}$ and ${ }^{\circledR}$ Min Wang ${ }^{1}$ \\ ${ }^{1}$ Department of Neuroscience, Yale University School of Medicine, New Haven, Connecticut 06520, and ${ }^{2}$ Center for Neuropsychiatric Diseases, Institute of \\ Life Science, Nanchang University, Nanchang 330031, China
}

\begin{abstract}
Noradrenergic (NE) $\alpha 1$-adrenoceptors ( $\alpha 1$-ARs) contribute to arousal mechanisms and play an important role in therapeutic medications such as those for the treatment of posttraumatic stress disorder (PTSD). However, little is known about how $\alpha 1$-AR stimulation influences neuronal firing in the dorsolateral prefrontal cortex (dIPFC), a newly evolved region that is dysfunctional in PTSD and other mental illnesses. The current study examined the effects of $\alpha 1$-AR manipulation on neuronal firing in dlPFC of rhesus monkeys performing a visuospatial working memory task, focusing on the "delay cells" that maintain spatially tuned information across the delay period. Iontophoresis of the $\alpha 1-A R$ antagonist HEAT (2-\{[ $\beta$-(4-hydroxyphenyl)ethyl $]$ aminomethyl $\}$-1-tetralone) had mixed effects, reducing firing in a majority of neurons but having nonsignificant excitatory effects or no effect in remaining delay cells. These data suggest that endogenous NE has excitatory effects in some delay cells under basal conditions. In contrast, the $\alpha 1$-AR agonists phenylephrine and cirazoline suppressed delay cell firing and this was blocked by coadministration of HEAT. These results indicate an inverted-U dose response for $\alpha 1$-AR actions, with mixed excitatory actions under basal conditions and suppressed firing with high levels of $\alpha 1$-AR stimulation such as with stress exposure. Immunoelectron microscopy revealed $\alpha 1$-AR expression presynaptically in axons and axon terminals and postsynaptically in spines, dendrites, and astrocytes. It is possible that $\alpha 1$-AR excitatory effects arise from presynaptic excitation of glutamate release, whereas postsynaptic actions suppress firing through calcium-protein kinase $\mathrm{C}$ opening of potassium channels on spines. The latter may predominate under stressful conditions, leading to loss of dlPFC regulation during uncontrollable stress.
\end{abstract}

Key words: alpha-1 receptor; dorsolateral prefrontal cortex; mental disorders; noradrenergic receptor; PTSD; working memory

Significance Statement

Noradrenergic stimulation of $\alpha 1$-adrenoceptors ( $\alpha 1$-ARs) is implicated in posttraumatic stress disorder (PTSD) and other mental disorders that involve dysfunction of the prefrontal cortex, a brain region that provides top-down control. However, the location and contribution of $\alpha 1$-ARs to prefrontal cortical physiology in primates has received little attention. This study found that $\alpha 1$-ARs are located near prefrontal synapses and that $\alpha 1$-AR stimulation has mixed effects under basal conditions. However, high levels of $\alpha 1$-AR stimulation, as occur with stress, suppress neuronal firing. These findings help to explain why we lose top-down control under conditions of uncontrollable stress when there are high levels of noradrenergic release in brain and why blocking $\alpha 1-\mathrm{AR}$, such as with prazosin, may be helpful in the treatment of PTSD.

\section{Introduction}

It has been long appreciated that noradrenergic (NE) stimulation of $\alpha 1$-adrenoceptors ( $\alpha 1$-ARs) contributes to cortical arousal

\footnotetext{
Received Sept. 25, 2018; revised Jan. 23, 2019; accepted Jan. 28, 2019.

Author contributions: J.S., Y.M.M., J.A., and A.D. edited the paper; D.D., A.F.T.A., and M.W. designed research; D.D., S.-T.Y., V.C.G., J.S., F.L., Y.M.M., J.A., A.D., and M.W. performed research; P.R. contributed unpublished reagents/analytic tools; D.D., S.-T.Y., V.C.G., A.F.T.A., and M.W. analyzed data; D.D., A.F.T.A., and M.W. wrote the paper.

This work was supported by the National Institutes of Health (Pioneer Award DP1AG047744-01 to A.F.T.A. and Grants DA02399 and EY002593 to P.R.). We thank Lisa Ciavarella, Tracy Sadlon, Sam Johnson, and Michelle Wilson for their technical expertise.
}

(Waterhouse et al., 1981; McCormick et al., 1991; Berridge and España, 2000). NE has varied interactions with adrenergic receptors, with high affinity for the $\alpha 1 \mathrm{~d}-\mathrm{AR}$ and $\alpha 2 \mathrm{~A}-\mathrm{AR}$ subtypes, but low affinity for the $\alpha 1 \mathrm{~A}-\mathrm{AR}$ and $\beta$-AR subtypes (Horie et al., 1995; Arnsten, 2000). Therefore, differing receptor mechanisms become engaged with increasing NE release; low to none during sleep, moderate levels in the alert, nonstressed state, and high

\footnotetext{
The authors declare no competing financial interests.

Correspondence should be addressed to Min Wang at min.wang@yale.edu.

https://doi.org/10.1523/JNEUROSCI.2472-18.2019
}

Copyright $\odot 2019$ the authors 
levels of release during psychological or physiological stress (Goldstein et al., 1996; Kobori et al., 2006). $\alpha 1$-AR actions are especially evident under stressful conditions of high NE release, when they strengthen the affective functioning of the amygdala (Ferry et al., 1999; Rajbhandari et al., 2015) but weaken the cognitive abilities of the prefrontal cortex (PFC) (Birnbaum et al., 1999). Therefore, they are particularly relevant to disorders such as posttraumatic stress disorder (PTSD).

Treatment of PFC disorders often involves medications that have $\alpha 1$-AR-blocking actions. For example, PTSD symptoms involve impaired PFC regulation of emotion (Fitzgerald et al., 2018) and the $\alpha 1$-AR antagonist prazosin is in widespread use for the treatment of PTSD in veterans, active duty soldiers, and civilians (for review, see Arnsten et al., 2015). $\alpha 1$-AR blockade is also a common characteristic of atypical antipsychotic drug actions (Baldessarini et al., 1992; Bymaster et al., 1996) used to treat mental disorders that involve dysfunction of the dorsolateral PFC (dlPFC; Glantz and Lewis, 2000). However, despite this therapeutic relevance, relatively little is known about the cellular actions of $\alpha 1$-ARs in primate dlPFC.

The primate dIPFC contains the neuronal microcircuits needed for visuospatial working memory, with "delay cells" that maintain spatially tuned firing across the delay period (Goldman-Rakic, 1995). This persistent firing arises from recurrent excitatory connections between layer III pyramidal cells (Kritzer and GoldmanRakic, 1995) and relies on NMDAR synapses on spines (Wang et al., 2013b; Ma et al., 2015). Cognitive data initially suggested that NE $\alpha 1$-ARs had little influence on dlPFC working memory function because infusions of the $\alpha 1$-AR antagonist prazosin into the monkey dlPFC had no effect on working memory performance (Li and Mei, 1994). However, later research showed that infusion of the $\alpha 1$-AR agonist phenylephrine (PE) produced a marked, delay-related impairment in performance (Mao et al., 1999) similar to that seen in rat mPFC (Arnsten and Jentsch, 1997). Because stress-induced cognitive deficits could be blocked by $\alpha 1$-AR antagonist infusion in rat mPFC (Birnbaum et al., 1999), the data suggested that $\alpha 1$-AR actions were only engaged in PFC when high levels of NE release were induced by stress exposure and that they suppressed dIPFC neuronal firing and function via activation of calcium-protein kinase C (PKC) signaling (Birnbaum et al., 2004). In contrast, in vitro physiological and behavioral studies in rats indicated that NE $\alpha 1$-ARs can have excitatory actions in $\mathrm{mPFC}$, for example, via increasing glutamate release (Zhang et al., 2013), and contributes to cognitive improvement (Puumala et al., 1997; Lapiz and Morilak, 2006; Berridge et al., 2012; Hvoslef-Eide et al., 2015), suggesting apparent species differences. However, $\alpha 1$-AR cellular actions in monkey dlPFC have received minimal examination and thus may be more similar to rat than presently thought.

The current study provides the first comprehensive examination of $\alpha 1$-AR cellular actions in monkey dlPFC. We examined the effects of local iontophoresis of $\alpha 1$-AR agents directly onto dIPFC neurons in monkeys performing a visuospatial working memory task, assessing the $\alpha 1$-AR antagonist HEAT ( $2-\{[\beta-(4-$ hydroxyphenyl)ethyl] aminomethyl\}-1-tetralone) to reveal the influence of endogenous NE $\alpha 1$-AR actions, as well as two $\alpha 1$-AR agonists, $\mathrm{PE}$ and cirazoline. We also performed immunoelectron microscopy (immuno-EM) of layer III monkey dlPFC to determine the ultrastructural localization of $\alpha 1$-ARs and how they compare to rat mPFC, in which $\alpha 1$-ARs have been found both presynaptically and postsynaptically (Mitrano et al., 2014). We found the first physiological evidence of an $\alpha 1$-AR inverted- $\mathrm{U}$ dose response, where presynaptic versus postsynaptic effects may promote excitatory versus suppressive actions on dlPFC delay cell firing.

\section{Materials and Methods}

Physiological recordings in cognitively engaged monkeys

Subjects. Two male, adult rhesus monkeys (Macaca mulatta) were used in the current study and were cared for under the guidelines of the National Institutes of Health (NIH) and the Yale Institutional Animal Care and Use Committee (IACUC).

Oculomotor delayed response (ODR) task. The monkeys were seated in primate chairs with their heads fixed and faced a 27 -inch computer monitor 30 inches in front of them. The monkeys' eye positions were monitored with the ISCAN Eye Movement Monitoring System. The monkeys were pretrained on the visuospatial ODR task, which required the subject to make a memory-guided saccade to a remembered visuospatial target. Patients with schizophrenia have been shown to be impaired on a human version of this task (Keedy et al., 2006). The ODR task was generated by the PICTO system (custom-designed, Windows-based data acquisition software). The task is illustrated in Figure 1A. A central small white circle was illuminated on the computer monitor, which served as the fixation target. To initiate a trial, the animal fixated this central target and maintained fixation for $0.5 \mathrm{~s}$ (fixation period), whereupon a cue (the same sized white circle) was illuminated for a period of $0.5 \mathrm{~s}$ (cue period) at 1 of 8 peripheral targets located at an eccentricity of $13^{\circ}$ with respect to the fixation spot. After the cue was extinguished, a $2.5 \mathrm{~s}$ delay period followed. The subject was required to maintain central fixation throughout both the cue presentation and the delay period. At the end of the delay, the fixation spot was extinguished, which instructed the monkey to make a memory-guided saccade to the location where the cue had been shown before the delay period. A trial was considered successful if the subject's response was completed within $0.5 \mathrm{~s}$ of the offset of the fixation spot and was within $2^{\circ}$ around the correct cue location. The subject was rewarded with fruit juice immediately after every successful response. The position of the stimulus was randomized over trials such that it had to be remembered on a trial-by-trial basis. The intertrial intervals (ITIs) were at least $3 \mathrm{~s}$. The subject performed 1000-1500 trials per session.

Recording locus. Before recording, the animals underwent a magnetic resonance image (MRI) scan to aid in the placement of a recording chamber over the caudal principal sulcus (as illustrated in Fig. 1B) and to later guide electrophysiological recordings. MRI-compatible materials were used for the implant so that a second MRI could be performed after implantation to confirm recording chamber position.

In vivo single-unit recordings and iontophoresis. Iontophoresis was used to apply the $\alpha 1$-AR agonists PE and cirazoline and/or the $\alpha 1$-AR antagonist HEAT hydrochloride, near dIPFC neurons. PE, cirazoline, and HEAT hydrochloride were from Tocris Bioscience. Drug solutions (5-10 $\mathrm{mm}, \mathrm{pH}=3-4)$ were made using sterilized water. Iontophoretic electrodes were constructed with a $20-\mu \mathrm{m}$-pitch carbon fiber (ELSI) inserted in the central barrel of a seven-barrel nonfilamented capillary glass (Friedrich and Dimmock). The assembly was pulled using a multipipette electrode puller (PMP-107L; Microdata Instrument) and the tip was beveled to obtain the finished electrode. Finished electrodes had impedances of $0.3-1.5 \mathrm{M} \Omega($ at $1 \mathrm{kHz}$ ) and tip sizes of $30-40 \mu \mathrm{m}$. The outer barrels of the electrode were then filled with three drug solutions (two consecutive barrels each) and the solutions were pushed to the tip of the electrode using compressed air. A Neurophore BH2 iontophoretic system (Medical Systems) was used to control the delivery of the drugs. The drug was ejected at currents that varied from 10 to $100 \mathrm{nA}$. Retaining currents of -5 to $-10 \mathrm{nA}$ were used in a cycled manner ( $1 \mathrm{~s}$ on, $1 \mathrm{~s}$ off) when not applying drugs. Drug ejection did not create noise in the recording and there was no systematic change in either spike amplitude or time course at any ejection current.

The electrode was mounted on a MO-95 micromanipulator (Narishige) in a 25 gauge stainless steel guide tube. The dura mater was punctured using the guide tube to facilitate access of the electrode into the cortex. Extracellular voltage was amplified using a AC/DC differential preamplifier (Model 3000; A-M Systems) and band-pass filtered $(180 \mathrm{~Hz}$ to $6 \mathrm{kHz}, 20 \mathrm{~dB}$ gain, 4-pole Butterworth; Kron-Hite). Signals were digitized (15 kHz, micro 1401; Cambridge Electronics Design) and acquired 
A

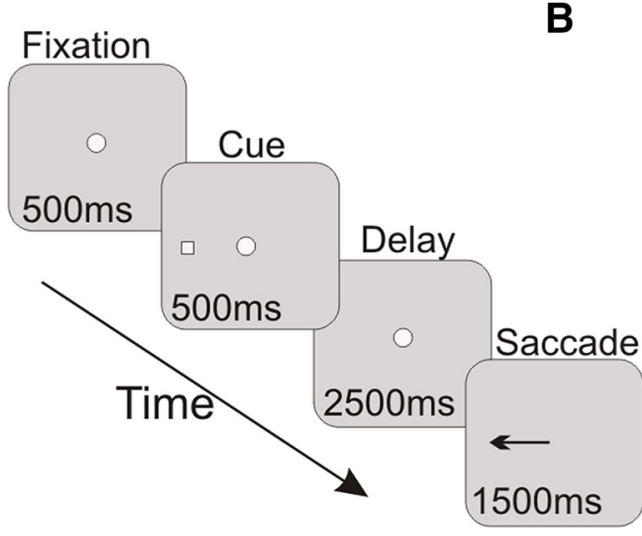

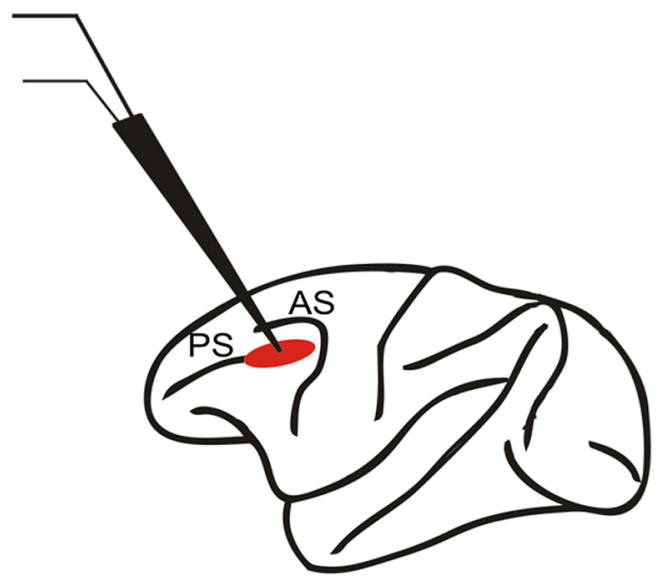

C
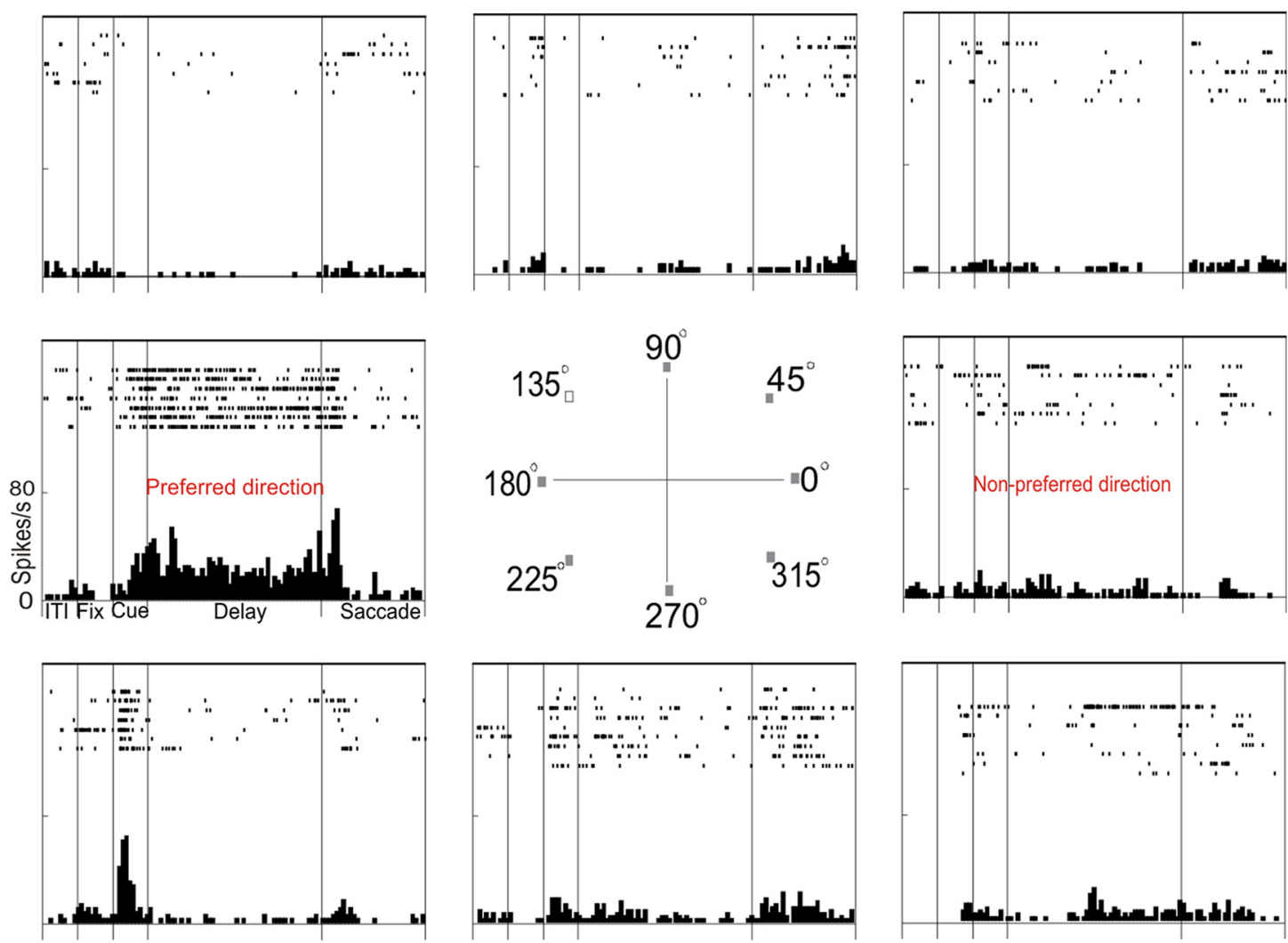

Figure 1. Paradigm used for iontophoretic recordings in monkeys performing a spatial working memory task. $\boldsymbol{A}$, The ODR spatial working memory task. $\boldsymbol{B}$, Region of the caudal principal sulcal (PS) PFC where recordings are performed. AS, Arcuate sulcus. C, Typical dIPFC delay cell with spatially tuned, delay-related firing. Rasters and histograms are arranged to indicate the location of the corresponding cue. Only the preferred direction and one nonpreferred direction will be shown in subsequent figures to conserve space.

using the Spike2 software (Cambridge Electronics Design). Neuronal activity was analyzed using waveform sorting by a template-matching algorithm. Poststimulus time histograms (PSTHs) and rasters were constructed online to determine the relationship of unit activity to the task. Unit activity was measured in spikes per second. We classified four different kinds of ODR task-related cells: fixation cells, cue cells, delay cells, and response cells. If the rasters showed that a neuron displayed taskrelated activity, then recording continued and pharmacological testing was performed. A total of 54 delay cells were recorded and tested with agents ( 32 from Monkey H, 22 from Monkey J).

Neuronal activities were first collected from the cell under a control condition in which at least eight trials at each of eight cue locations were obtained. A typical delay cell is shown in Figure 1C. Upon establishing the stability of the cells' activity, this control condition was followed by iontophoretic application of drug(s). Dose-dependent effects of the drug were tested in two or more consecutive conditions, followed by a recovery condition or a reversal condition. Each condition had approximately eight (range, six to 12) trials at each location to allow for statistical analyses of drug effects. Recovery conditions are especially important for treatments that reduce firing to demonstrate that the neuron is still healthy. However, given the prolonged effects of many compounds, such as through second messenger actions, a statistically significant but not complete restoration to baseline was required. Drugs were continuously applied at a relevant current throughout a given condition. Please note that the term "dose" signifies "iontophoretic dose" herein because the amount of drug released is proportional to the ejection current. However, it is impossible to know the exact amount of drug released and the extent of drug dispersal into brain tissue because this varies based on many factors including the lipophilicity of the compound and the exact placement of the electrode in regard to nearby white matter. However, it 
is the only method that allows application of drug without disturbing the position of the underlying neuron because there is no fluid ejection to move the neuron away from the electrode. Finally, it is common for the arousal neuromodulators such as NE and dopamine (DA) to produce an inverted-U dose response on dlPFC cell firing. For example, DA stimulation of D1R has an inverted-U dose response, in which both D1R antagonists and D1R agonists suppress firing (Williams and GoldmanRakic, 1995; Vijayraghavan et al., 2007). This is especially common when animals are working under optimal arousal conditions, as in our studies.

Data analyses. Each trial in the ODR task was divided into four epochs: initial fixation, cue, delay and response (saccade). The initial fixation epoch lasted for $0.5 \mathrm{~s}$. The cue epoch lasted for $0.5 \mathrm{~s}$ and corresponds to the stimulus presentation phase of the task. The delay lasted for $2.5 \mathrm{~s}$ and reflects the mnemonic component of the task. The response phase started immediately after the delay epoch and lasted $\sim 1.5 \mathrm{~s}$. Data analysis was performed in MATLAB and SPSS. Spike density functions were constructed in $50 \mathrm{~ms}$ windows. Two-way ANOVA was used to examine the spatial tuned task-related activity with regard to different periods of the task (fixation, cue, delay, and response vs ITI) and different cue locations. This study focused on delay cells that represent working memory. Many delay cells fire during the cue and/or response epochs as well as the delay epoch; given their variable responses to the cue and response epochs, data analyses focused on the delay epoch using the entire delay period $(0-2.5 \mathrm{~s})$. One-way ANOVA or $t$ test were used to assess the effects of drug application on task-related activity. In the interest of brevity, figures often show the neurons' preferred direction compared with just one nonpreferred direction, the "anti-preferred" direction directly opposed to the neurons' preferred direction. For delay cells, spatial tuning was assessed by comparing firing levels for the neuron's preferred direction vs its nonpreferred directions. Quantification of spatial tuning was performed by calculating a measure of $d^{\prime}$ using the following formula:

$$
d^{\prime}=\left(\text { mean }_{\text {pref }}-\text { mean }_{\text {nonpref }}\right) / \sqrt{\left(s d_{\text {pref }}^{2}+s d_{\text {nonpref }}^{2}\right) / 2}
$$

\section{Electron microscopy}

Tissue processing. Fixed, long-term-stored rhesus monkey brain tissue from one female monkey (age of 18 years) was used for this study. In general, brain tissues were prepared for storage in our brain bank as follows, with euthanasia performed in accordance with the guidelines of the Yale IACUC and NIH's Guidelines for the Care and Use of Experimental Animals. Monkeys were deeply anesthetized before transcardial perfusion of artificial CSF, followed by $4 \%$ paraformaldehyde $/ 0.05 \%$ glutaraldehyde in $100 \mathrm{~mm}$ PBS. Following perfusion, a craniotomy was performed and the entire brain was removed and dissected, including a frontal block containing the primary region of interest surrounding the principal sulcus. The brains were sectioned coronally at $60 \mu \mathrm{m}$ on a vibratome (Leica) across the entire rostrocaudal extent of the dIPFC (Walker's area 46). The sections were cryoprotected through increasing concentrations of sucrose solution $(10 \%, 20 \%$, and $30 \%$ each for $2 \mathrm{~h}$ and then $30 \%$ overnight), cooled rapidly using liquid nitrogen, and stored at $-80^{\circ} \mathrm{C}$.

Histology and immunoreagents. The antibody used to detect $\alpha 1$-AR in the current study (PA1-047; Thermo Scientific) is the same one used by the Weinshenker group (Mitrano et al., 2012,2014) to localize $\alpha 1$-ARs in rat PFC. This rabbit polyclonal antibody has been extensively characterized and was raised against a synthetic peptide corresponding to residues K(339)FSREKKAKT(349) of the third intracellular loop of human $\alpha 1$ AR. It has been previously shown to recognize $\alpha 1$-ARs with a high degree of specificity in different tissues and cell types by Western blot and immunohistochemistry procedures (Nakadate et al., 2001; Wee et al., 2008; Cognato et al., 2010; Rajbhandari et al., 2015). We further validated specificity by performing a peptide adsorption control experiment using the PA1-047 immunizing peptide (Thermo Fisher Scientific, catalog \#PEP-216) in which no positive labeling was observed. Normal sera and IgG-free BSA were from Jackson Immunoresearch.

Pre-embedding peroxidase immunocytochemistry. Sections of dlPFC were processed for $\alpha 1$-AR immunocytochemistry. To enable penetration of immunoreagents, all sections went through three freeze-thaw cycles in liquid nitrogen. Nonspecific reactivity was suppressed with 10\% NGS and $2 \%$ BSA and antibody penetration was enhanced with $0.3 \%$ Triton
X-100 in 50 mm TBS. As described previously (Paspalas et al., 2013), dlPFC sections were incubated for $72 \mathrm{~h}$ at $4^{\circ} \mathrm{C}$ with $\alpha 1$-AR antibody in TBS, and transferred for $2 \mathrm{~h}$ at room temperature to species-specific biotinylated $\mathrm{Fab}^{\prime}$ or $\mathrm{F}\left(\mathrm{ab}^{\prime}\right)_{2}$ fragments in TBS. Sections were incubated with the avidin-biotin peroxidase complex $(\mathrm{ABC})$ (1:300; Vector Laboratories) and then visualized in $0.025 \%$ 3,3-diaminobenzidine tetrahydrochloride (DAB; Sigma-Aldrich) as a chromogen in $100 \mathrm{~mm}$ PB with the addition of $0.005 \%$ hydrogen peroxide for $10 \mathrm{~min}$. After the DAB reaction, sections were exposed to osmification, dehydration, and epoxy resin embedding on microscope slides. Omission of $\alpha 1$-AR primary antibody or substitution with nonimmune rabbit serum resulted in a complete lack of immunoperoxidase labeling.

Electron microscopy and data analysis. All sections were processed as described previously (Paspalas et al., 2013). Briefly, blocks containing dIPFC layer III were dissected and mounted onto resin blocks. The specimens were cut into $50 \mathrm{~nm}$ sections using an ultramicrotome (Leica) and analyzed under a JEM1010 transmission electron microscope (Jeol) at 80 $\mathrm{kV}$. Several plastic blocks of each brain were examined using the fourth to $12^{\text {th }}$ surface-most sections of each block (i.e., 200-600 nm) to sample the superficial component of sections, avoiding penetration artifacts. Structures were digitally captured at $25,000 \times$ to $100,000 \times$ magnification with a Bioscan camera and individual panels were adjusted for brightness and contrast using Adobe Photoshop and Illustrator CC.2017.01 image editing software. Approximately 300 micrographs of selected areas of neuropil with immunopositive profiles were used for analyses. For profile identification, we adopted the criteria summarized by Peters et al. (1991). Dendritic spines in the PFC are typically long and thin, devoid of mitochondria, and contain a noticeable postsynaptic density at asymmetric synapses. Dendritic shafts were typically round in perpendicular planes or elongated when assessed in horizontal planes, usually containing mitochondria and numerous tubular and pleomorphic cellular organelles. Numerous dendritic shafts received synaptic inputs. Axon terminals contained accumulations of synaptic vesicles and the axoplasm of these terminals usually contained neurofilaments and mitochondria. The synaptic innervations made by these axon terminals were either asymmetric, containing spherical vesicles, or symmetric, containing pleomorphic vesicles, with thick or thin postsynaptic density, respectively. Unmyelinated axons were small, round processes with a predominantly even and regular shape, traversing the neuropil in a straight orientation, often forming bundles in perpendicular planes. Astroglial processes were typically of irregular morphology and filled the space around neuronal elements.

\section{Results}

\section{Physiology}

Effects of blocking endogenous NE stimulation of $\alpha 1-A R$ with the antagonist HEAT

We first examined the effect of blocking $\alpha 1$-AR on the delayrelated firing in dlPFC delay cells to assess the role of endogenous NE stimulation $\alpha 1$-AR on working memory function in awake behaving animals. Although behavioral studies had found little influence on working memory performance when an $\alpha 1$-AR antagonist was infused into the dlPFC (Li and Mei, 1994), it is not known how local $\alpha 1$-AR blockade would effect dlPFC neuronal firing. Here, we trained two monkeys to perform an ODR spatial working memory task while recording from delay cells in area 46 of dlPFC (Fig. 1). The $\alpha 1$-AR antagonist HEAT hydrochloride was delivered via iontophoresis near the neurons under investigation. In this experiment, 14 neurons with delay-related mnemonic activity were isolated and tested with HEAT. We found that HEAT had a mixed effect on PFC delay-related firing. As shown in Figure 2A, HEAT caused a significant decrease in delayrelated firing in 8 of 14 delay cells, consistent with endogenous NE having excitatory actions under basal conditions. However, HEAT produced either a nonsignificant increase in firing or no change in firing in the remaining six delay cells. A single-cell example of HEAT decreasing firing is shown in Figure $2 B$ (con- 
trol vs HEAT at $15 \mathrm{nA}, p=0.005, t_{(11)}=$ 4.87, unpaired $t$ test) and a single-cell example of its tendency to increase firing in another neuron is shown in Figure $2 C$ (control vs HEAT at $15 \mathrm{nA}, p=0.35$, $t_{(12)}=0.96$, unpaired $t$ test). Overall, when the 14 neurons were combined, HEAT produced a significant reduction in firing $\left(p=0.047, t_{(13)}=2.195\right.$, two-tailed paired $t$ test).

Effects of stimulating $\alpha 1-A R s$ with the agonists $P E$ and cirazoline

In contrast to the mixed effects of HEAT, stimulation of $\alpha 1$-ARs with agonists had a more consistent effect, suppressing neuronal firing. We tested two $\alpha 1-\mathrm{AR}$ agonists, $\mathrm{PE}$ and cirazoline, over a wide range of doses. Our previous work had examined only very high-dose PE administration (Birnbaum et al., 2004), so a more comprehensive characterization was needed. A total of 30 delay cells were tested with PE (25-50 nA) and PE was found to significantly suppress firing in 27 of the 30 cells. As illustrated in Figure $3 A$, iontophoretic application of $\mathrm{PE}$ produced a dose-related reduction in delay-related firing. $\mathrm{PE}$ at dose of $25 \mathrm{nA}$ significantly reduced the delay activity for the neuron's preferred direction (control vs $\mathrm{PE}$ at 25 $\mathrm{nA}, p=0.026, t_{(15)}=2.474$, unpaired $t$ test), but not for its nonpreferred direction (control vs PE at $25 \mathrm{nA}, p=0.66$, $t_{(15)}=0.43$, unpaired $t$ test), whereas a higher dose of PE (40 nA) further suppressed delay firing for the neuron's preferred direction (control vs $\mathrm{PE}$ at $25 \mathrm{nA}$, $p=0.036, t_{(11)}=2.38$, unpaired $t$ test). The suppressing effects of PE were consistent at the population level. Figure $3 B$ shows the averaged effect of PE on delay cell firing in all 30 delay cells tested. Statistical analysis showed that PE application significantly reduced neuronal firing during the delay epoch for the neurons' preferred direction (Fig. $3 C ; p=0.0003$, $t_{(30)}=4.087$, two-tailed paired $t$ test), but not the nonpreferred direction (Fig. $3 C$; $p=0.12, t_{(30)}=1.588$, two-tailed paired $t$ test) for all 30 delay cells. To confirm that $\mathrm{PE}$ reduced direction selectivity, we calculated a measure of $d^{\prime}$ to determine whether PE eroded the spatial tuning of delay cells. This measure captures how well a delay cell can represent a spatial position over the delay epoch in the absence of sensory stimulation and thus is particularly important to the strength of working memory. A greater $d^{\prime}$ value indicates greater directional selectivity, that is, greater spatial tuning. A total of 26 of 30 delay cells showed significantly lower $d^{\prime}$ in the PE condition compared with the control condition (Fig. 3D; $p<0.0001, t_{(30)}=5.544$, two-tailed paired $t$ test).
A

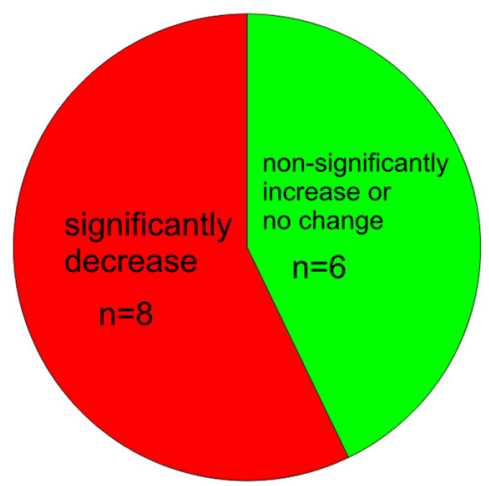

B Control Preferred Direction

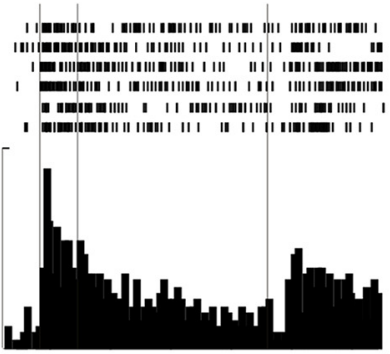

HEAT@15nA

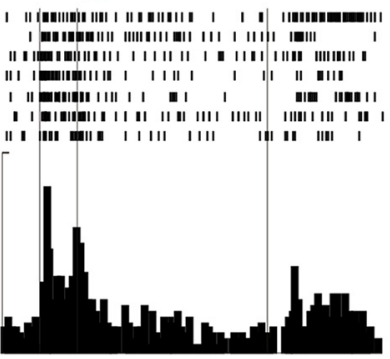

recovery

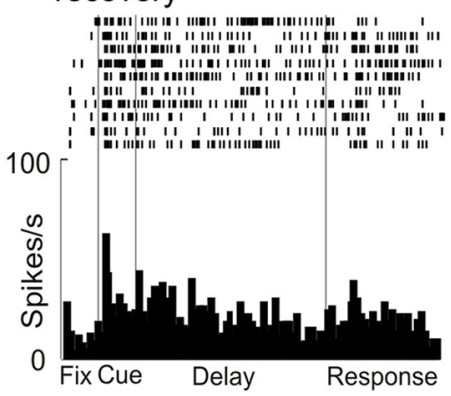

C

$$
\text { Control Preferred Direction }
$$

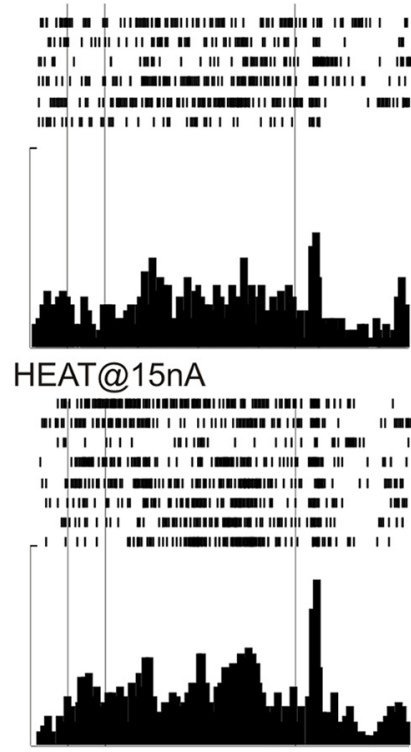

HEAT@25nA

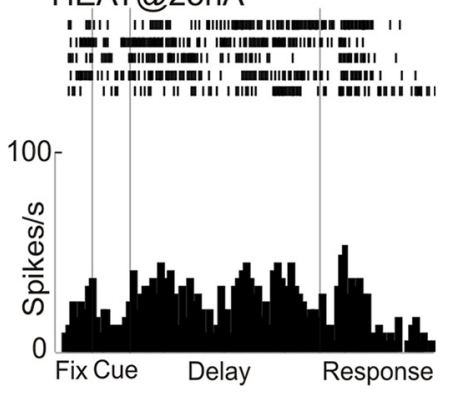

Figure 2. Effects of the $\alpha 1$-AR antagonist HEAT on the delay-related firing of dIPFC delay cells. $\boldsymbol{A}$, The $\alpha 1$-AR antagonist HEAT had mixed effects on delay-related firing: it significantly decreased firing in eight delay cells and had no effect or produced a nonsignificant increase in firing for the remaining six delay cells. $\boldsymbol{B}$, Single-neuron example of the reduction in task-related firing following HEAT as seen in most neurons, including significant recovery toward baseline when drug was removed. $C$, Single-neuron example of the excitatory effects of HEAT. Only the preferred direction is shown to facilitate comparison.

PE excited delay-related firing in three of the 30 delay cells at the same doses that suppressed firing in the majority of neurons. An example of PE's excitatory effect is shown in Figure 4. In this case, PE significantly enhanced the delay activity for the neuron's preferred direction (control vs PE at $40 \mathrm{nA}, p=0.049, t_{(14)}=2.156$, unpaired $t$ test), but not for its nonpreferred direction (control vs PE at $40 \mathrm{nA}$, $p=0.095, t_{(15)}=1.779$, unpaired $t$ test) and increased the spatial tuning (2.3 for the control condition to 3.1 for the PE condition). However, these enhancing effects were remarkably rare. 
A
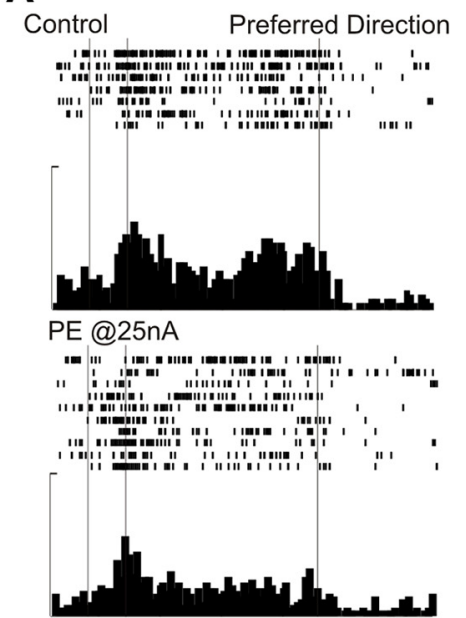

PE@40nA
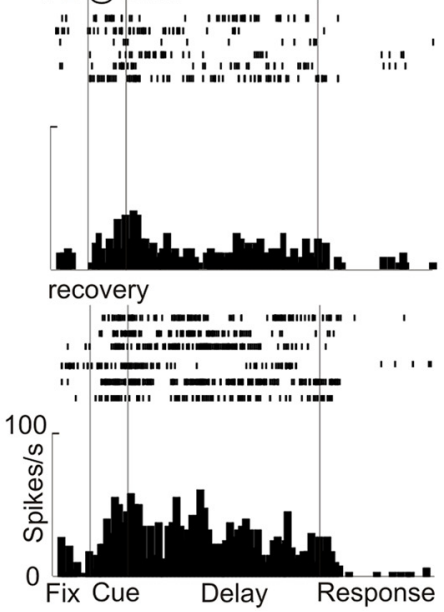

B
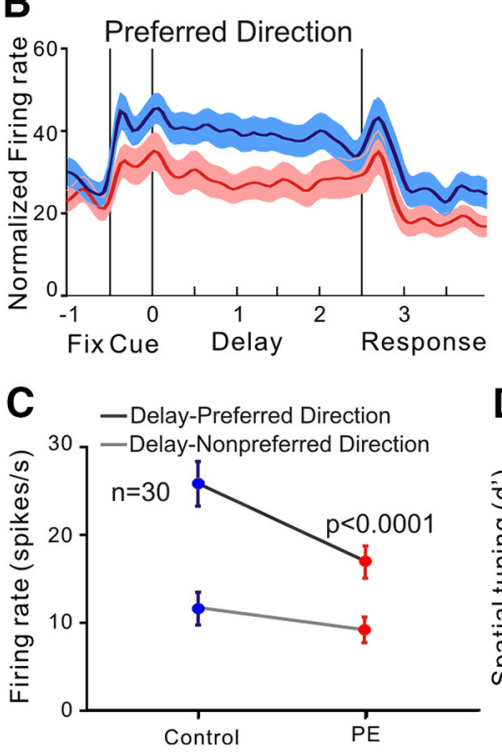
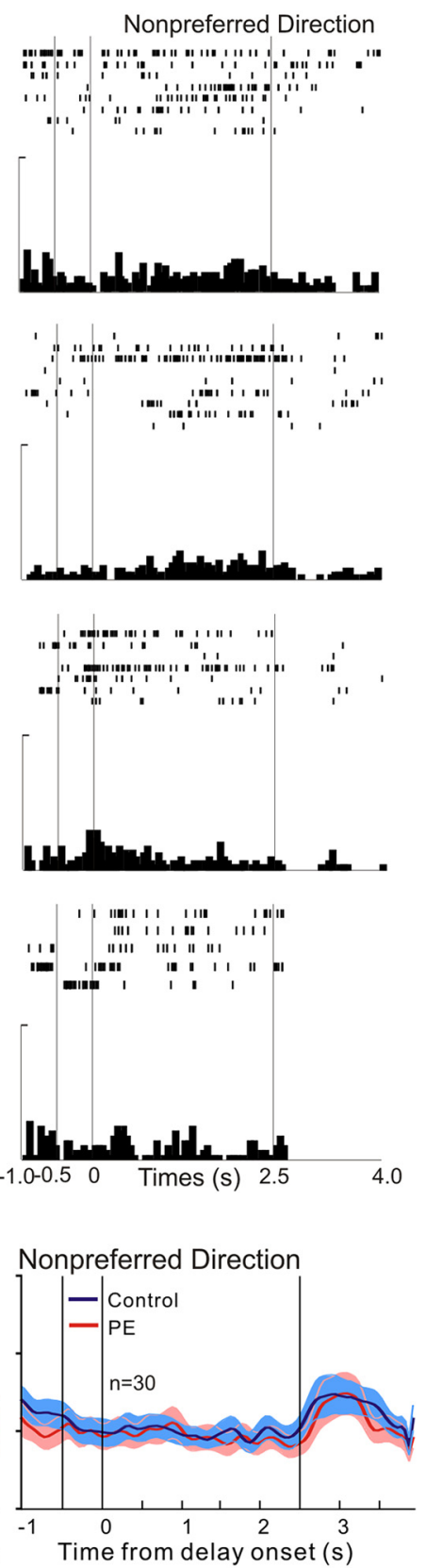

D

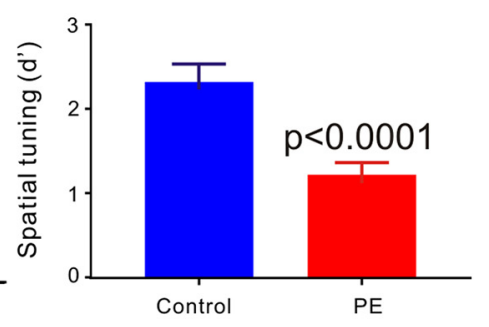

Figure 3. Effects of the $\alpha 1-A R$ agonist PE on the delay-related firing of dIPFC delay cells. $\boldsymbol{A}$, Single-neuron example of the dose-dependent effects of $P E$ on delay-related firing. Raster and histogram data are shown for four different conditions: control, PE at $25 \mathrm{nA}, \mathrm{PE}$ at $40 \mathrm{nA}$, and recovery. PE produced a dose-dependent decrease in delay-related firing selectively for the neuron's preferred direction. $B$, Population response of the effects of $P E$ on delay-related firing showing the normalized average firing rate of 30 delay cells for their preferred versus their nonpreferred directions under control conditions (blue) and following iontophoresis of PE (red). C, Mean \pm SEM firing rate of these same 30 delay cells during the delay period of the task. Statistical analysis showed that PE significantly reduced the delay firing for the preferred direction, but not for the nonpreferred direction. $D$, Iontophoresis of PE significantly decreased the spatial tuning of delay cells by decreasing $d^{\prime}$.

The second $\alpha 1$-AR agonist cirazoline consistently suppressed delay-related firing in 10 of 10 delay cells tested. As shown in Figure $5 \mathrm{~A}$, cirazoline produced a doserelated reduction in delay-related firing, with marked suppression following $40 \mathrm{nA}$ (control vs cirazoline at $25 \mathrm{nA}, p=0.02$, $t_{(12)}=2.659$, unpaired $t$ test; control vs cirazoline at $40 \mathrm{nA}, p<0.0001, t_{(15)}=$ 9.884, unpaired $t$ test). Delay-related firing returned toward control levels when the drug was no longer applied (recovery condition; recovery vs cirazoline at $40 \mathrm{nA}$, $p<0.0001, t_{(17)}=5.128$, unpaired $t$ test). The suppressing effects of cirazoline were highly consistent at the population level (Fig. 5B). Statistical analysis showed that cirazoline significantly reduced neuronal firing during the delay epoch for the neurons' preferred direction (Fig. $5 C ; p=$ $0.001, t_{(11)}=4.313$, two-tailed paired $t$ test), but not for the nonpreferred direction (Fig. $5 C ; p=0.194, t_{(11)}=1.382$, two-tailed paired $t$ test). Similar to the effects of PE, iontophoresis of cirazoline significantly reduced the spatial tuning of delay cell firing during the delay epoch by decreasing $d^{\prime}$ (Fig. $5 D ; p=0.002, t_{(11)}=$ 4.052, two-tailed paired $t$ test).

Challenging the PE response with HEAT

To test whether the suppressing effects of PE occurred through actions at $\alpha 1$-ARs, we coapplied the $\alpha 1$-AR antagonist HEAT with PE and found that HEAT could prevent the suppressing effects of PE. As shown in Figure 6A, HEAT at a low dose of $10 \mathrm{nA}$ produced a slight, nonsignificant reduction in delay-related firing for the neuron's preferred direction. When PE was then coapplied with HEAT, firing was unchanged. However, when HEAT was no longer applied, PE markedly suppressed delay-related firing. HEAT's ability to block the suppressive effects of PE action was established in $5 / 5$ neurons (Fig. $6 B$; overall: $p=0.85$, Friedman test; pairwise comparisons: control vs HEAT: $p=$ 0.81 ; HEAT vs HEAT +PE: $p=0.81$, Wilcoxon signed-rank test). These results are consistent with PE acting at $\alpha 1-\mathrm{AR}$.

\section{Immuno-EM}

$\alpha 1-A R$ distribution in presynaptic and postsynaptic neuronal compartments in monkey dlPFC

We found significant $\alpha 1$-AR labeling in both presynaptic and postsynaptic neuronal compartments in primate layer III dIPFC (Fig. 7). Presynaptic $\alpha 1$-AR labeling could be seen in both asymmetric axon terminals and unmyelinated axons. Within axon terminals, $\alpha 1$-AR were often found perisynaptically or extrasynapti- 
cally bordering the excitatory synapse along the axolemma, but were not observed within the active zone per se (Fig. $7 A$ ). In addition to the terminal distribution, $\alpha 1$-ARs in axons were also observed in preterminal axons or intervaricose segments traversing through the neuropil, which may represent receptors trafficking to the terminal (data not shown).

The predominant postsynaptic localization of $\alpha 1$-AR was in dendritic spines (Fig. $7 B$ ). Labeling was especially evident on spines with long, thin necks, a prominent postsynaptic density (PSD), and a spine apparatus (the extension of the calcium-storing, smooth endoplasmic reticulum into the spine), all common features in primate layer III dlPFC. The labeling was often observed extrasynaptically or perisynaptically to glutamatergiclike axospinous asymmetric synapses, usually in close proximity to the spine apparatus (Fig. 7B). Expression of $\alpha 1$-ARs was not detected in spines receiving symmetric synapses. Dendritic shafts also expressed $\alpha 1-\mathrm{AR}$ immunoreactivity at nonsynaptic membranes, as well as within the intracellular compartment, possibly being trafficked along microtubules to distal sections of the neuron (data not shown).

Localization of $\alpha 1$-ARs in astrocytic processes in monkey dlPFC layer III

$\alpha 1$-ARs were also prominent in dlPFC layer III astrocytes (Fig. 8). The labeling pattern was targeted to perisynaptic astrocytic processes ensheathing axospinous synapses (Fig. 8A,B). Occasionally, $\alpha 1$-AR-labeled astrocytic processes near axodendritic glutamatergic-like synapses in close proximity to dendritic mitochondria (Fig. $8 C$ ). The labeling pattern was most pronounced along the astroglial plasma membrane and not diffusely distributed throughout the cytoplasm.

In summary, $\alpha 1$-ARs were observed in both presynaptic and postsynaptic compartments of neurons, as well as in astroglial processes.

\section{Discussion}

The current data show the first evidence of an NE $\alpha 1$-AR inverted- $U$ dose response on delay cell firing in the primate dlPFC and the first ultrastructural data showing $\alpha 1$-AR expression presynaptically on axon terminals and postsynaptically on layer III spines (schematically illustrated in Fig. 9). The physiological recordings revealed excitatory effects of endogenous NE at $\alpha 1$-AR under nonstress conditions in a large subset of neurons because there was reduced neuronal firing when these actions were blocked by HEAT. Low doses of the $\alpha 1$-AR agonist PE also produced excitatory effects in a small number of neurons, suggesting that the prevalent $\alpha 1$-AR response under basal NE, nonstress conditions is excitatory (Fig. 9). In contrast, iontophoresis of higher doses of PE and cirazoline predominately suppressed firing and this reduction was reversed by co-iontophoresis with HEAT, consistent with $\alpha 1$-AR drug actions. The suppression of firing with high levels of $\alpha 1$-AR stimulation likely occurs during
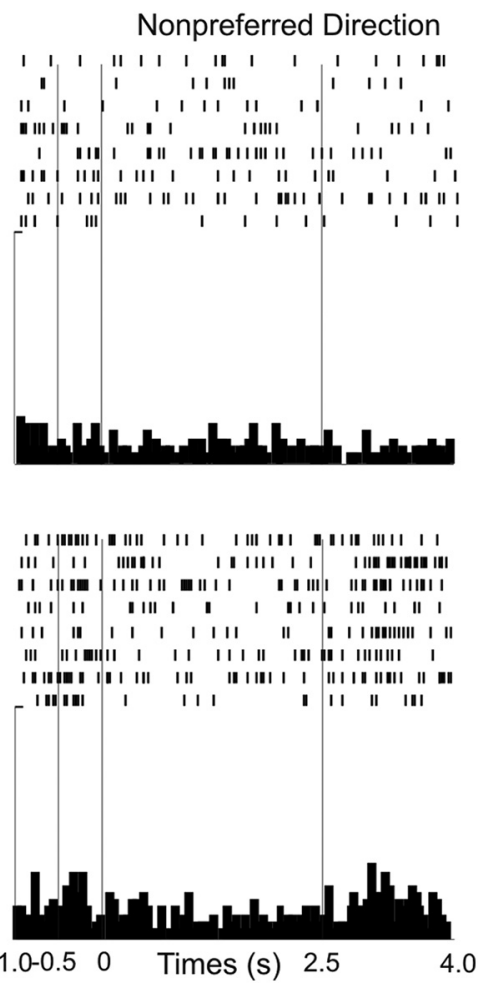

$\begin{array}{llll}-1.0-0.5 & 0 & \text { Times (s) } & 2.5\end{array}$

Figure 4. Single-neuron example of PE's excitatory effects on delay-related firing. Three delay cells showed increased firing following iontophoresis of PE. In the example shown here, PE at $40 \mathrm{nA}$ significantly enhanced the delay activity for the neuron's preferred direction, but not for its nonpreferred direction.

stress exposure (Fig. 9) when there are very high levels of NE release in PFC (Nakane et al., 1994; Finlay et al., 1995) and dlPFC function is rapidly impaired (Arnsten, 2009).

Immuno-EM showed that the predominant location of $\alpha 1-\mathrm{AR}$ is on spines, suggesting that drugs acted directly on pyramidal cells. However, given the architecture of dlPFC microcircuits, reduced pyramidal cell firing would also decrease interneuron firing. Waveform analyses are inadequate to definitively characterize cell recordings as pyramidal cells or interneurons, but the data suggest an overall reduction in dlPFC microcircuit activity following $\alpha 1$-AR stimulation.

The excitatory actions of endogenous, basal levels of NE versus the suppressive effects of cirazoline may arise from their differing affinity for $\alpha 1$-AR subtypes. NE has much higher affinity for $\alpha 1 \mathrm{~d}$-AR (42 nM) than for $\alpha$ la-AR (990 nM), whereas cirazoline has the opposite profile ( $\alpha$ la-AR: $120 \mathrm{~nm}$ vs $\alpha 1 \mathrm{~d}-\mathrm{AR}: 660 \mathrm{~nm}$; Horie et al., 1995). In contrast, $\mathrm{PE}$ is nonselective between subtypes (Minneman et al., 1994). It is possible that $\alpha 1$-AR excitatory effects in primate dlPFC involve $\alpha 1 \mathrm{~d}$-AR actions, for example, increasing presynaptic glutamate release, whereas the suppressive effects involve $\alpha 1 \mathrm{a}-\mathrm{AR}$ actions, for example, at postsynaptic receptors that engage calciumPKC- $\mathrm{K}^{+}$signaling (Datta and Arnsten, 2018). The latter idea is supported by in vitro data showing that the $\alpha$ la-AR subtype engages PKC signaling more potently than $\alpha 1$ d-ARs (Taguchi et al., 1998). However, there are currently no $\alpha 1$ d-AR-selective compounds that would allow testing of this hypothesis.

\section{Species comparisons for rat versus monkey immuno-EM $\alpha 1$-ARs}

The general pattern of $\alpha 1-\mathrm{AR}$ expression at the ultrastructural level is schematically illustrated in Figure $9 B$ and is remarkably similar between rat mPFC (layer V/VI) and monkey dlPFC layer 
A
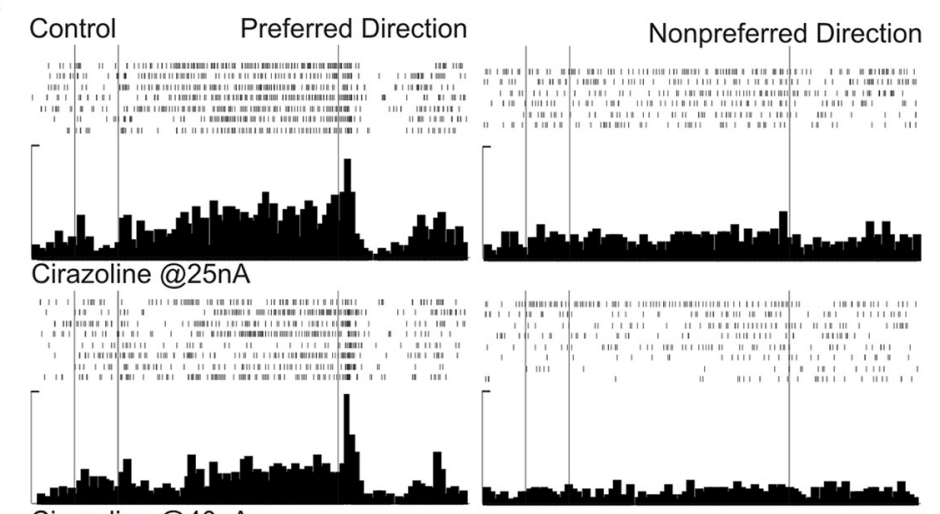

Cirazoline @40nA

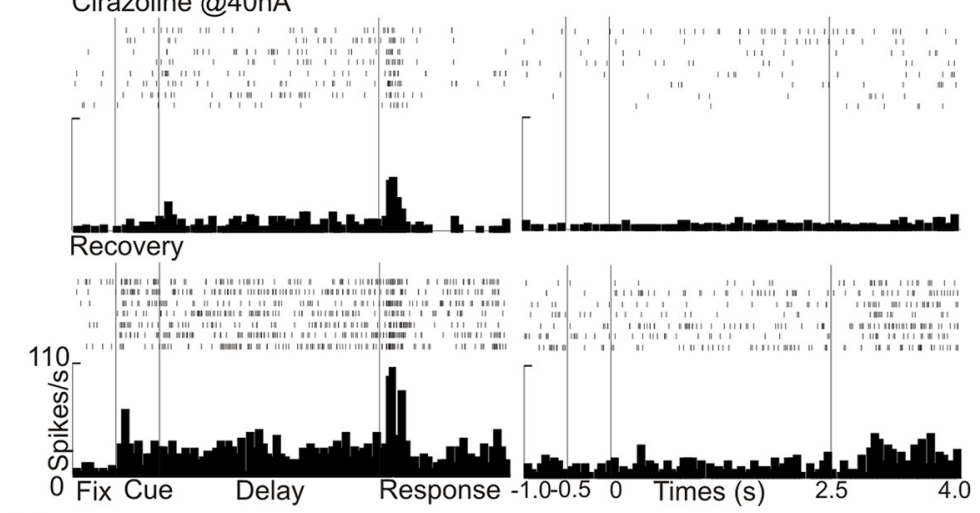

B

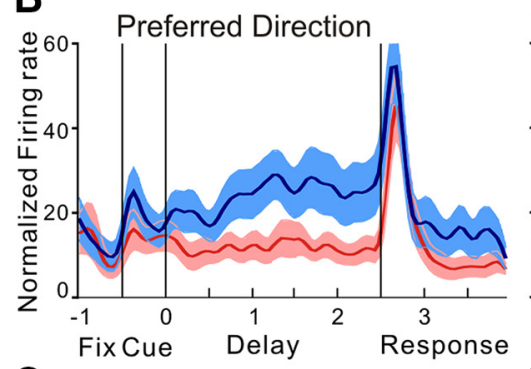

C

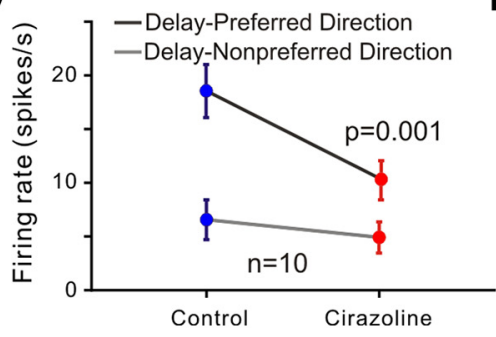

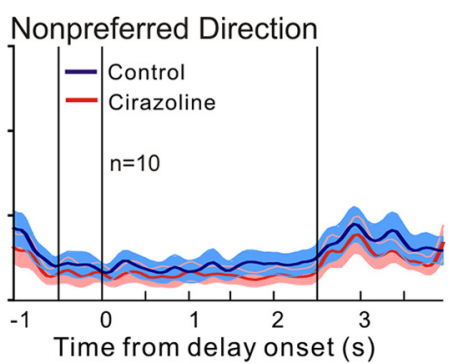

D

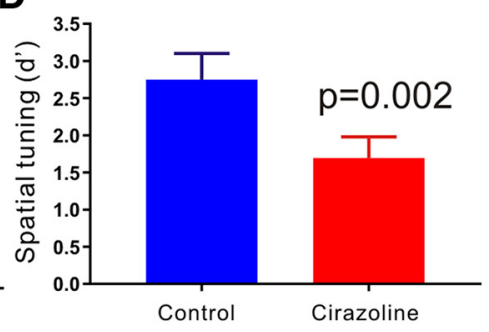

Figure 5. Effects of the $\alpha 1$-AR agonist cirazoline on the delay-related firing of dIPFC delay cells. $\boldsymbol{A}$, Single-neuron example of the dose-dependent effects of cirazoline on delay-related firing. Raster and histogram data are shown for four different conditions: control conditions, cirazoline at $25 \mathrm{nA}$, cirazoline at $40 \mathrm{nA}$, and recovery. Cirazoline produced a dose-dependent decrease in delay-related firing selectively for the neuron's preferred direction. $\boldsymbol{B}$, Population response of the effects of cirazoline on delayrelated firing showing the normalized average firing rate of 10 delay cells for their preferred versus their nonpreferred directions under control conditions (blue) and following iontophoresis of cirazoline (red). C, Mean \pm SEM firing rate of these same 10 delay cells during the delay period of the task. Statistical analysis shows that cirazoline significantly reduced the delay firing for the preferred direction, but not for the nonpreferred direction. $\boldsymbol{D}$, Iontophoresis of cirazoline significantly decreased the spatial tuning of delay cells by decreasing $d^{\prime}$.

III. The Weinshenker group (Mitrano et al., 2012, 2014) has described $\alpha 1$-AR labeling in rat mPFC on unmylinated axons and axon terminals and on spines and dendrites, with most of the dendritic labeling in the cytoplasm likely trafficking to more distal aspects of the cell. A similar pattern was seen in monkey, with axonal labeling in both nonterminal and terminal regions and the spine labeling occasionally within the PSD, but mostly distant from the synapse often near the calcium-containing spine apparatus. $\alpha 1-\mathrm{AR}$ in the PSD may phosphorylate NMDARs to maintain receptors in the synapse and promote excitatory actions, as suggested by physiological recordings in rat mPFC (Luo et al., 2014), whereas $\alpha 1$-ARs more distant from the PSD may engage calcium-cAMP- $\mathrm{K}^{+}$channel actions that reduce firing (Datta and Arnsten, 2018).

A key difference between the rat and monkey was the pronounced expression of $\alpha 1$-ARs in glia (likely astrocytes) in monkey layer III dlPFC, but not in rat mPFC. $\alpha 1$-ARs have been shown to mediate the calcium waves that coordinate excitation across wide cortical regions (Ding et al., 2013), which may play a larger role in the expanded primate cortex.

\section{Species comparisons for rat versus monkey $\alpha 1$-AR physiology}

Direct comparisons of $\alpha 1$-AR actions in rat versus monkey $\mathrm{PFC}$ are challenging due to a number of factors. The PFC subregion under investigation is different (mPFC in rats vs dlPFC in monkeys) and the physiological studies in rat $\mathrm{mPFC}$ are from in vitro slice recordings from juvenile animals (P20-P23), usually from layer $\mathrm{V}$ neurons, under conditions in which there is no endogenous NE release. Therefore, the ascending side of the inverted-U dose response curve would be accentuated in these preparations and, indeed, these studies find excitatory effects of $\alpha 1$-AR stimulation involving both increased presynaptic glutamate release (Zhang et al., 2013; Luo et al., 2014) and facilitation of postsynaptic NMDAR and AMPAR actions (Luo et al., 2014). In vitro studies of rat $\mathrm{mPFC}$ have also found that $\alpha 1$-AR can reduce glutamatergic drive on GABA interneurons (Wang et al., 2013a), which may disinhibit cortex.

In contrast, the monkey studies are in vivo recordings from delay cells (likely layer III) from the dIPFC of adult, cognitively engaged animals with active NE release. The current study found the first evidence of endogenous NE having excitatory actions at $\alpha 1$-AR in monkey dlPFC and the immuno-EM suggests these may involve some of the same subcellular actions as in rat, for example, enhancing glutamate release and promoting NMDAR actions in the PSD. However, additional $\alpha 1$-AR stimulation with PE and especially cirazoline suppressed delay cell firing, suggesting that our monkeys are typically performing with optimal levels of NE $\alpha 1$-AR stimulation and that 
A

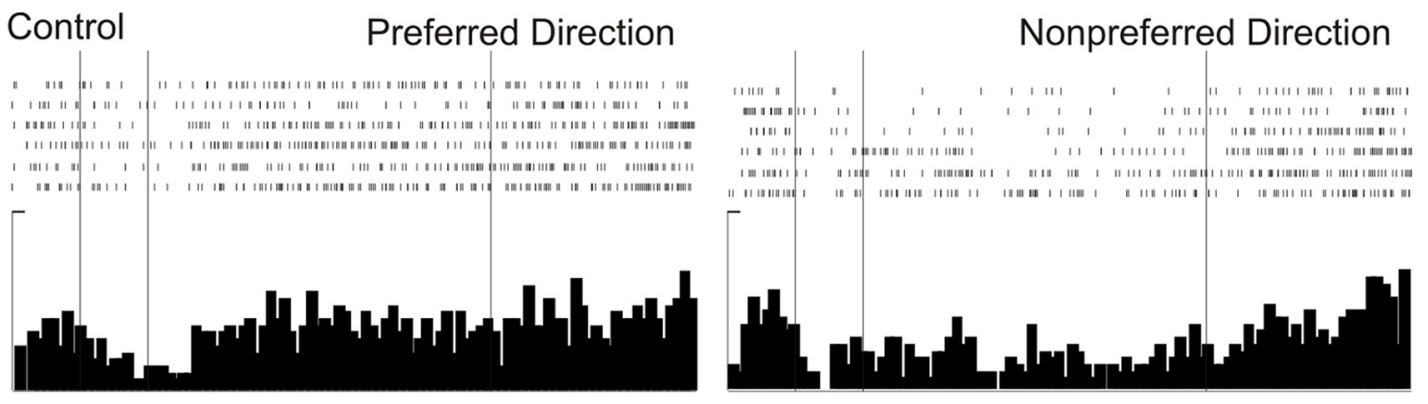

\section{HEAT@10nA}
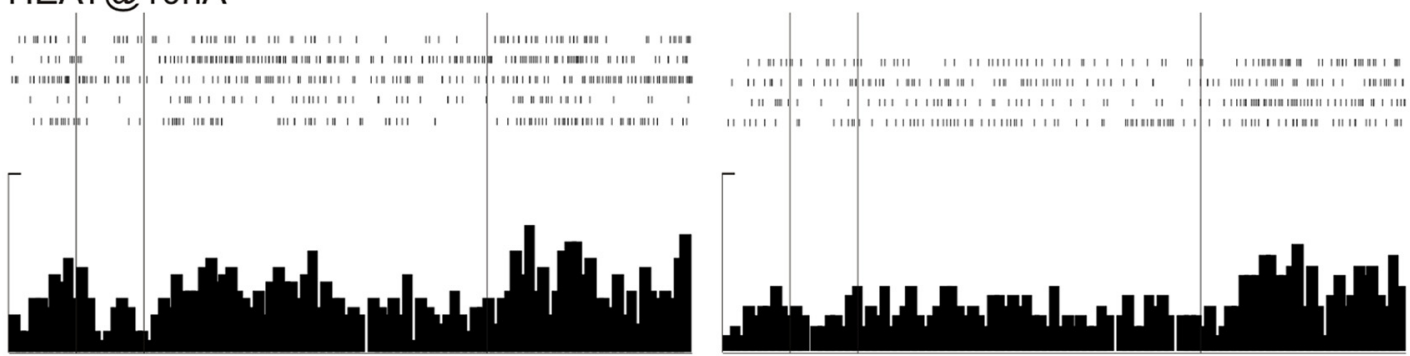

HEAT@10nA+PE@25nA
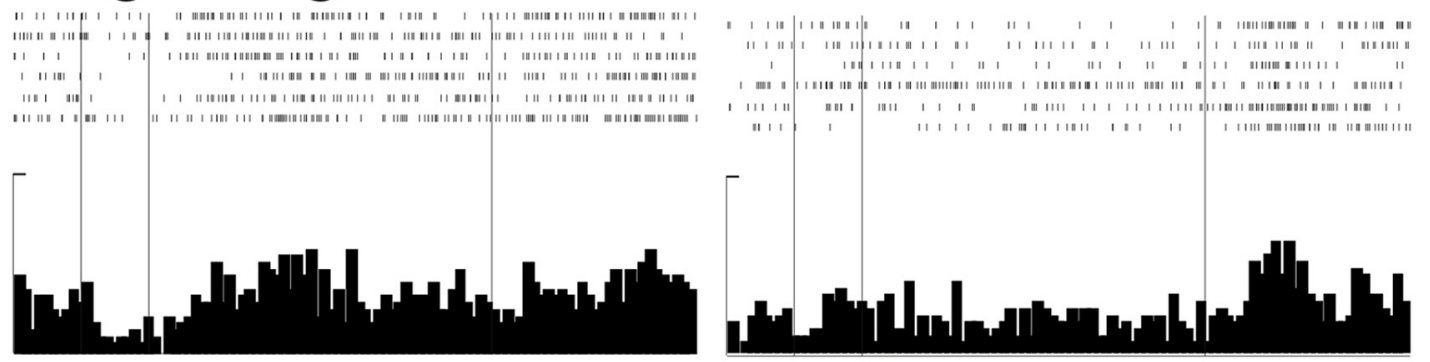

PE @25nA

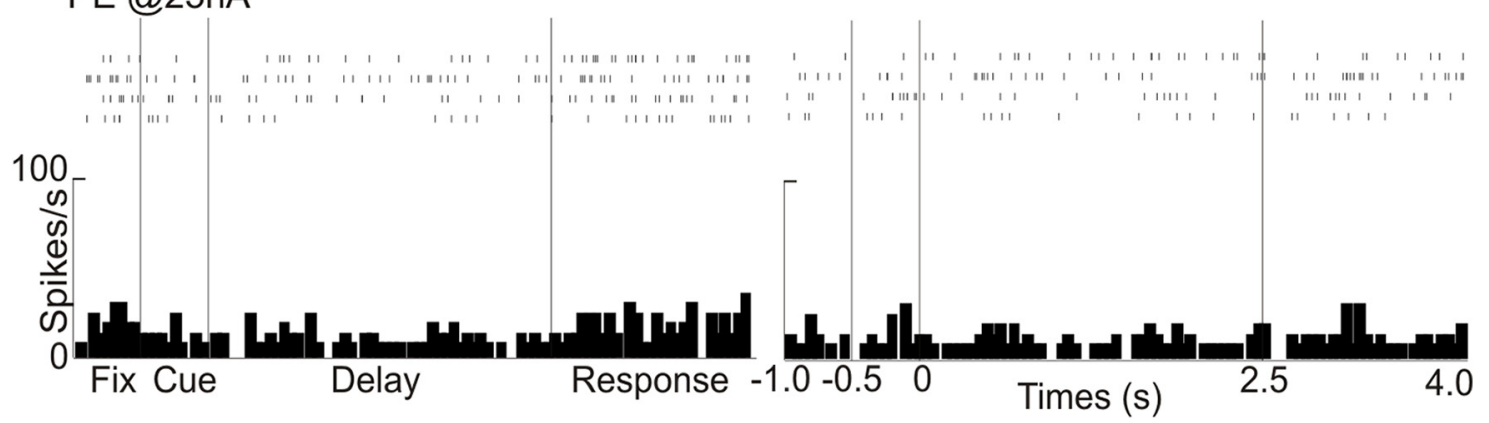

B
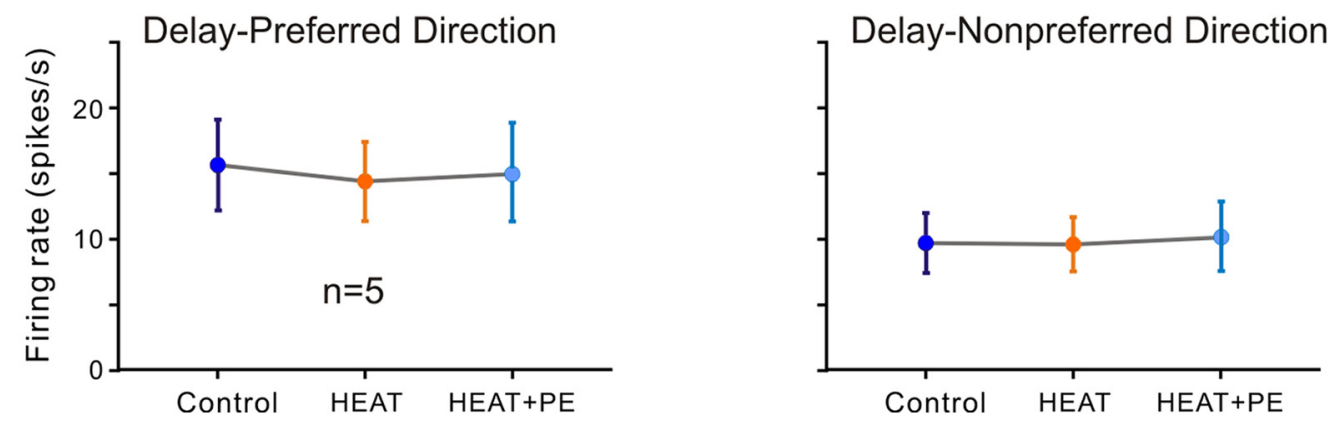

Figure 6. Iontophoresis of an $\alpha 1$-AR antagonist blocked the suppressive effects of an $\alpha 1$-AR agonist. $A$, Single-neuron example showing that the $\alpha 1$-AR antagonist HEAT at a low dose of $10 \mathrm{nA}$ produced a nonsignificant reduction in delay-related firing for the neuron's preferred direction. When PE was then coapplied with HEAT, firing was unchanged. Bottom, When HEAT was no longer applied and PE was administered by itself, PE dramatically suppressed delay-related firing. $\boldsymbol{B}$, HEAT's ability to block the suppressive effects of PE action was established in $5 / 5$ neurons. 

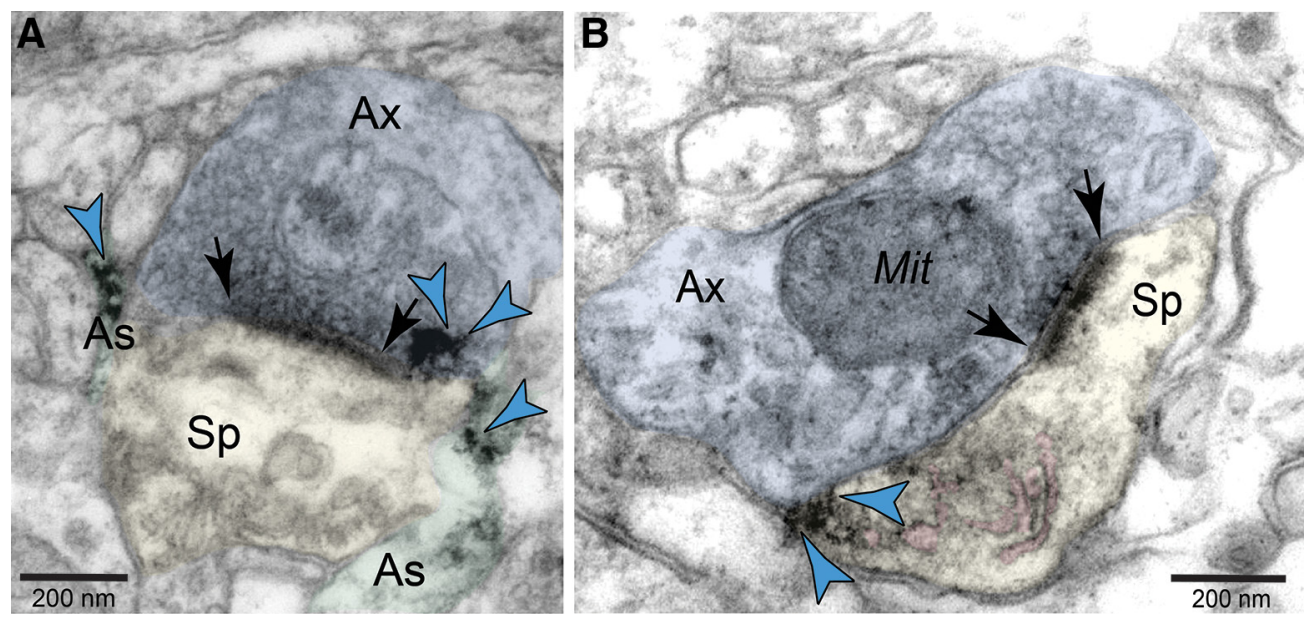

Figure 7. Neuronal expression of $\alpha 1$-AR in monkey dIPFC layer III. A, $\alpha 1$-ARs are expressed in glutamatergic-like axon terminals establishing asymmetric axospinous synapses. Typically, the immunolabeling is visualized on membranes flanking the synapse in perisynaptic or extrasynaptic locations. Note that $\alpha 1$-ARs are also present in astroglial processes surrounding such synapses (see Fig. 8). $\boldsymbol{B}, \alpha 1$-ARs are prominently expressed in dendritic spines adjacent to glutamatergic-like, axospinous, asymmetric synapses. As seen in this example, they are usually in extrasynaptic and/or perisynaptic locations, often in close proximity to the calcium-containing spine apparatus (pink-pseudocolored), the extension of the smooth endoplasmic reticulum into the spine head. Labeled profiles are pseudocolored for clarity; blue arrowheads point to $\alpha 1$-AR; synapses are between arrows. Sp, Spine; Den, dendrite; Ax, axon.
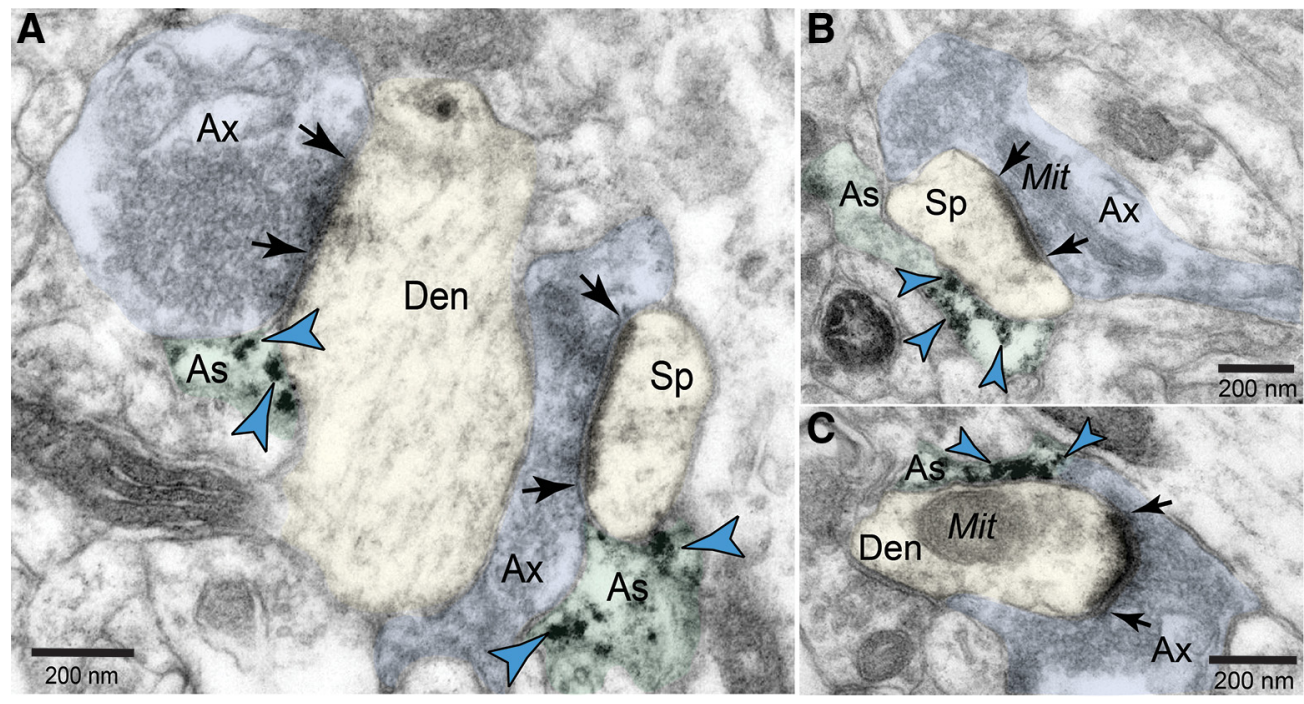

Figure 8. Astrocytic expression of $\alpha 1$-AR in monkey dIPFC layer III. $A, B, \alpha 1$-AR labeling is observed in perisynaptic astrocytic leaflets ensheathing axospinous asymmetric synapses. Note that $\alpha 1$-AR labeling is not distributed uniformly throughout the astrocytic plasma membrane, but is enriched in close proximity to the synapse. An astrocyte surrounding an axodendritic synapse in $A$ is also reactive against $\alpha 1$-ARs near the synapse. $C, \alpha 1$-AR immunoreactivity can also be captured in astrocytes around axodendritic glutamatergic-like synapses in close proximity to postsynaptic mitochondrial profiles. Labeled profiles are pseudocolored for clarity; blue arrowheads point to $\alpha 1$-AR; synapses are between arrows. Sp, Spine; Den, dendrite; Ax, axon; As, astroglial.

excessive activation suppresses firing. These cellular data explain why both PE infusion directly into monkey dlPFC (Mao et al., 1999) or systemic administration of cirazoline (Arnsten and Jentsch, 1997) impairs working memory performance in monkeys. Previous research indicates that these impairing actions involve calcium-PKC signaling (Birnbaum et al., 2004), which can drive feedforward calcium-PKC-cAMP signaling and reduce firing through opening of $\mathrm{K}^{+}$channels in layer III dlPFC spines (Datta and Arnsten, 2018) (Fig. 9B).

Overall, the excitatory versus suppressive postsynaptic effects of $\alpha 1$-AR-calcium-PKC signaling in spines may depend upon the level of $\mathrm{K}^{+}$channel expression and the levels of cytosolic calcium in that spine. Therefore, $\alpha 1$-AR stimulation may be predominately excitatory in spines with relatively few calciumcAMP-sensitive $\mathrm{K}^{+}$channels (SK, HCN, KCNQ) and with healthy calcium regulation, but may be predominately suppres- sive in spines where there are high levels of these $\mathrm{K}^{+}$channels (e.g., in layer III dlPFC; Arnsten, 2015) and/or dysregulated calcium signaling (e.g., due to inflammation or advanced age; $\mathrm{Oh}$ et al., 2013; Arnsten, 2015). Therefore, neurons excited by PE may have received less endogenous NE stimulation or may not have had the postsynaptic signaling machinery, for example, KCNQ channel expression, needed to suppress firing.

\section{Clinical relevance}

The evidence of an $\alpha 1$-AR inverted-U influence on dlPFC physiology is consistent with the contrasting roles of $\alpha 1$-AR mechanisms in treatments for mental disorders, in which increased $\alpha 1$-AR stimulation can contribute to medications treating under-aroused subjects, whereas $\alpha 1$-AR blockade is central to treating stress-related disorders such as PTSD. 


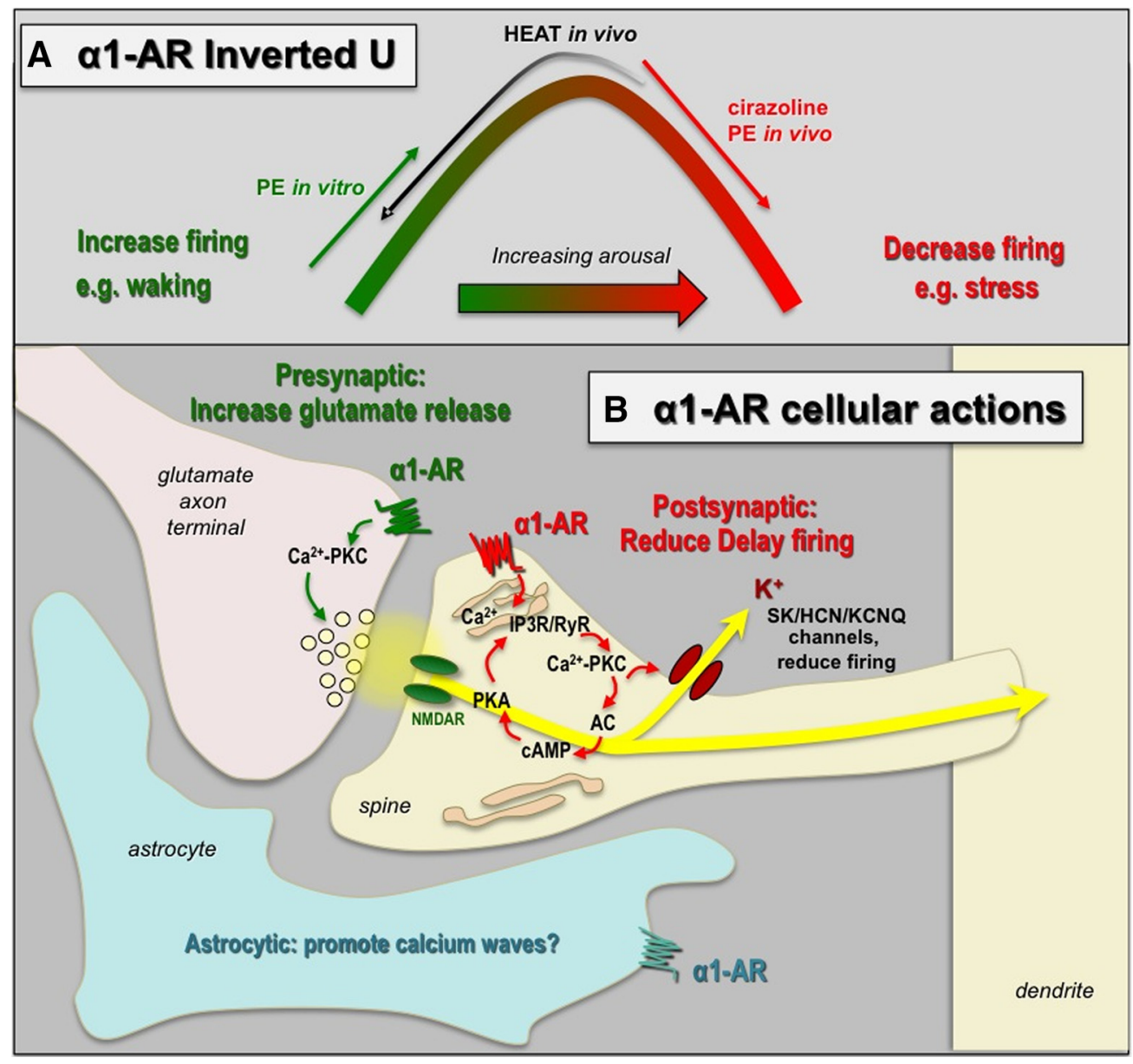

Figure 9. Schematic illustration of $\alpha 1$-AR actions in the primate dIPFC.A, Physiological data indicate an inverted-U dose response curve in which moderate levels of NE release under basal arousal conditions have excitatory effects in some neurons, whereas higher levels of $\alpha 1$-AR stimulation, for example, with agonist application or during stress, suppress firing. Because in vitro studies from rodent PFC have little or no NE present, these experiments are performed on the left side of the curve, whereas the current in vivo study was conducted under conditions of endogenous NE release, shown at the top of the curve. These differences in endogenous stimulation may help to explain some of the apparent discrepancies in the field. $\boldsymbol{B}$, Immuno-EM found $\alpha 1$-ARs in both presynaptic and postsynaptic locations. Physiological studies in rat PFC show that presynaptic $\alpha 1$-ARs can enhance glutamate release (Zhang et al., 2013) and excite neuronal firing. In contrast, postsynaptic $\alpha 1$-ARs on spines can reduce firing by increasing calcium-cAMP opening of $\mathrm{K}^{+}$channels in layer III dIPFC neurons (Arnsten, 2015).

Both animal and human studies suggest that medications to promote vigilance can involve $\alpha 1$-AR stimulation, although the effects are subtle. For example, methylphenidate's enhancement of sustained attention in rats is reduced by $\alpha 1$-AR blockade (Berridge et al., 2012). Similarly, an $\alpha 1$-AR antagonist blocks the improvement in executive function induced by modafinil in healthy human subjects (Winder-Rhodes et al., 2010). Modafinil is used to treat narcolepsy and fatigue (Murillo-Rodríguez et al., 2018). Therefore, boosting $\alpha 1$-AR actions may help subjects with insufficient, endogenous NE actions.

In contrast, $\alpha 1$-AR antagonists are now in widespread use for disorders associated with stress and excessive NE signaling. Stress worsens or causes a variety of disorders associated with PFC dysfunction, including depression, bipolar disorder, schizophrenia, and PTSD (Mazure, 1995). Animal studies also indicate that traumatic brain injury (TBI) may involve increased catecholamine release and $\alpha 1$-AR stimulation in PFC as a key etiological event (Kobori et al., 2006, 2011). There is some evidence of excessive NE $\alpha 1$-ARs in the dorsal PFC of suicide patients (Arango et al., 1993) and extensive evidence that PTSD involves excessive NE signaling (Southwick et al., 1993, 1999; O’Donnell et al., 2004).

Many treatments for stress-related disorders have $\alpha 1$-ARblocking properties. For example, atypical antipsychotic med- ications are used to treat PTSD and as adjunct therapy in treatment-resistant depression (Stein et al., 2002; Adetunji et al., 2005; Zhou et al., 2015). In addition to blocking D2R and 5HT2R, atypical antipsychotics have potent $\alpha 1$-AR-blocking properties (e.g.: $K_{\mathrm{i}}$ values for clozapine: $19 \mathrm{nM}$, risperidone: $2 \mathrm{nM}$, olanzapine: $7 \mathrm{nM}$; Bymaster et al., 1996). Although the therapeutic role of $\alpha 1$-AR blockade is only rarely discussed (Baldessarini et al., 1992), the current data suggest that this property may play an important therapeutic role in rescuing dlPFC neurons from the suppressive effects of excessive $\alpha 1$-AR stimulation.

Finally, the $\alpha 1$-AR antagonist prazosin is widely used to treat PTSD in veterans, active duty soldiers, and civilians, including those with TBI (Raskind et al., 2003, 2013; Taylor et al., 2006; Ruff et al., 2012; Koola et al., 2014). Furthermore, the longer-acting $\alpha 1-\mathrm{AR}$ antagonist doxazosin is in experimental use (Smith and Koola, 2016). Although the initial focus of prazosin research was on reducing nightmares, data also show reduced daytime PTSD symptoms, especially in those taking higher doses or longeracting treatments (Taylor et al., 2006; Ruff et al., 2012; Koola et al., 2014; Smith and Koola, 2016). Because PTSD symptomology is related to PFC dysfunction (Aupperle et al., 2012; Kühn and Gallinat, 2013; Fitzgerald et al., 2018), including weaker dlPFC regulation of emotional response (Aupperle et al., 2012), the cur- 
rent data suggest that restoration of dlPFC physiology with $\alpha 1$-AR blockade may be an important aspect of prazosin's therapeutic response. Although the current study used a spatial working memory task, dlPFC delay firing can also encode many aspects of top-down control, including affective value (Seo et al., 2007) and behavioral organization (Procyk and Goldman-Rakic, 2006). Therefore, $\alpha 1$-AR blockade may disinhibit dlPFC microcircuits during stress and allow generation of the representations needed to guide appropriate emotion and action in a healthy mental state.

\section{References}

Adetunji B, Mathews M, Williams A, Budur K, Mathews M, Mahmud J, Osinowo T (2005) Use of antipsychotics in the treatment of posttraumatic stress disorder. Psychiatry 2:43-47.

Arango V, Ernsberger P, Sved AF, Mann JJ (1993) Quantitative autoradiography of alpha 1- and alpha 2-adrenergic receptors in the cerebral cortex of controls and suicide victims. Brain Res 630:271-282.

Arnsten AF (2015) Stress weakens prefrontal networks: molecular insults to higher cognition. Nat Neurosci 18:1376-1385.

Arnsten AF (2000) Through the looking glass: differential noradrenergic modulation of prefrontal cortical function. Neural Plast 7:133-146.

Arnsten AF (2009) Stress signaling pathways that impair prefrontal cortex structure and function. Nat Rev Neurosci 10:410-422.

Arnsten AF, Jentsch JD (1997) The alpha-1 adrenergic agonist, cirazoline, impairs spatial working memory performance in aged monkeys. Pharmacol Biochem Behav 58:55-59.

Arnsten AF, Raskind MA, Taylor FB, Connor DF (2015) The effects of stress exposure on prefrontal cortex: translating basic research into successful treatments for post-traumatic stress disorder. Neurobiol Stress 1:89-99.

Aupperle RL, Allard CB, Grimes EM, Simmons AN, Flagan T, Behrooznia M, Cissell SH, Twamley EW, Thorp SR, Norman SB, Paulus MP, Stein MB (2012) Dorsolateral prefrontal cortex activation during emotional anticipation and neuropsychological performance in posttraumatic stress disorder. Arch Gen Psychiatry 69:360-371.

Baldessarini RJ, Huston-Lyons D, Campbell A, Marsh E, Cohen BM (1992) Do central antiadrenergic actions contribute to the atypical properties of clozapine? Br J Psychiatry Suppl 17:12-16.

Berridge CW, España RA (2000) Synergistic actions of b- and a1noradrenergic receptors in the maintenance of alert waking. Neuroscience 99:495-505.

Berridge CW, Shumsky JS, Andrzejewski ME, McGaughy JA, Spencer RC, Devilbiss DM, Waterhouse BD (2012) Differential sensitivity to psychostimulants across prefrontal cognitive tasks: differential involvement of noradrenergic $\alpha_{1 \text { - }}$ and $\alpha_{2}$-receptors. Biol Psychiatry 71:467-473.

Birnbaum SG, Yuan PX, Wang M, Vijayraghavan S, Bloom AK, Davis DJ, Gobeske KT, Sweatt JD, Manji HK, Arnsten AF (2004) Protein kinase C overactivity impairs prefrontal cortical regulation of working memory. Science 306:882-884.

Birnbaum S, Gobeske KT, Auerbach J, Taylor JR, Arnsten AF (1999) A role for norepinephrine in stress-induced cognitive deficits: alpha-1-adrenoceptor mediation in prefrontal cortex. Biol Psychiatry 46:1266-1274.

Bymaster FP, Calligaro DO, Falcone JF, Marsh RD, Moore NA, Tye NC, Seeman P, Wong DT (1996) Radioreceptor binding profile of the atypical antipsychotic olanzapine. Neuropsychopharmacology 14:87-96.

Cognato GP, Agostinho PM, Hockemeyer J, Müller CE, Souza DO, Cunha RA (2010) Caffeine and an adenosine $\mathrm{A}(2 \mathrm{~A})$ receptor antagonist prevent memory impairment and synaptotoxicity in adult rats triggered by a convulsive episode in early life. J Neurochem 112:453-462.

Datta D, Arnsten AF (2018) Unique molecular regulation of higher-order prefrontal cortical circuits: Insights into the neurobiology of schizophrenia. ACS Chem Neurosci 9:2127-2145.

Ding F, O'Donnell J, Thrane AS, Zeppenfeld D, Kang H, Xie L, Wang F, Nedergaard M (2013) $\alpha 1$-adrenergic receptors mediate coordinated $\mathrm{Ca} 2+$ signaling of cortical astrocytes in awake, behaving mice. Cell Calcium 54:10

Ferry B, Roozendaal B, McGaugh JL (1999) Basolateral amygdala noradrenergic influences on memory storage are mediated by an interaction between beta- and alpha-1-adrenoceptors. J Neurosci 19:5119-5123.

Finlay JM, Zigmond MJ, Abercrombie ED (1995) Increased dopamine and norepinephrine release in medial prefrontal cortex induced by acute and chronic stress: effects of diazepam. Neuroscience 64:619-628.

Fitzgerald JM, DiGangi JA, Phan KL (2018) Functional neuroanatomy of emotion and its regulation in PTSD. Harv Rev Psychiatry 26:116-128.

Glantz LA, Lewis DA (2000) Decreased dendritic spine density on prefrontal cortical pyramidal neurons in schizophrenia. Arch Gen Psychiatry 57:65-73.

Goldman-Rakic PS (1995) Cellular basis of working memory. Neuron 14:477-485.

Goldstein LE, Rasmusson AM, Bunney BS, Roth RH (1996) Role of the amygdala in the coordination of behavioral, neuroendocrine and prefrontal cortical monoamine responses to psychological stress in the rat. J Neurosci 16:4787-4798.

Horie K, Obika K, Foglar R, Tsujimoto G (1995) Selectivity of the imidazoline alpha-adrenoceptor agonists (oxymetazoline and cirazoline) for human cloned alpha 1-adrenoceptor subtypes. $\mathrm{Br} \mathrm{J}$ Pharmacol 116:1611-1618.

Hvoslef-Eide M, Oomen CA, Fisher BM, Heath CJ, Robbins TW, Saksida LM, Bussey TJ (2015) Facilitation of spatial working memory performance following intraprefrontal cortical administration of the adrenergic alpha 1 agonist phenylephrine. Psychopharmacology (Berl) 232:4005-4016.

Keedy SK, Ebens CL, Keshavan MS, Sweeney JA (2006) Functional magnetic resonance imaging studies of eye movements in first episode schizophrenia: smooth pursuit, visually guided saccades and the oculomotor delayed response task. Psychiatry Res 146:199-211.

Kobori N, Clifton GL, Dash PK (2006) Enhanced catecholamine synthesis in the prefrontal cortex after traumatic brain injury: implications for prefrontal dysfunction. J Neurotrauma 23:1094-1102.

Kobori N, Hu B, Dash PK (2011) Altered adrenergic receptor signaling following traumatic brain injury contributes to working memory dysfunction. Neuroscience 172:293-302.

Koola MM, Varghese SP, Fawcett JA (2014) High-dose prazosin for the treatment of post-traumatic stress disorder. Ther Adv Psychopharmacol 4:43-47.

Kritzer MF, Goldman-Rakic PS (1995) Intrinsic circuit organization of the major layers and sublayers of the dorsolateral prefrontal cortex in the rhesus monkey. J Comp Neurol 359:131-143.

Kühn S, Gallinat J (2013) Gray matter correlates of posttraumatic stress disorder: a quantitative meta-analysis. Biol Psychiatry 73:70-74

Lapiz MD, Morilak DA (2006) Noradrenergic modulation of cognitive function in rat medial prefrontal cortex as measured by attentional set shifting capability. Neuroscience 137:1039-1049.

Li BM, Mei ZT (1994) Delayed response deficit induced by local injection of the alpha-2 adrenergic antagonist yohimbine into the dorsolateral prefrontal cortex in young adult monkeys. Behav Neural Biol 62:134-139.

Luo F, Tang H, Li BM, Li SH (2014) Activation of $\alpha_{1}$-adrenoceptors enhances excitatory synaptic transmission via a pre- and postsynaptic protein kinase C-dependent mechanism in the medial prefrontal cortex of rats. Eur J Neurosci 39:1281-1293.

Ma L, Skoblenick K, Seamans JK, Everling S (2015) Ketamine-induced changes in the signal and noise of rule representation in working memory by lateral prefrontal neurons. J Neurosci 35:11612-11622.

Mao ZM, Arnsten AF, Li BM (1999) Local infusion of alpha-1 adrenergic agonist into the prefrontal cortex impairs spatial working memory performance in monkeys. Biol Psychiatry 46:1259-1265.

Mazure CM, ed (1995) Does stress cause psychiatric illness? Washington, DC: American Psychiatric Association.

McCormick DA, Pape HC, Williamson A (1991) Actions of norepinephrine in the cerebral cortex and thalamus: implications for function of the central noradrenergic system. Prog Brain Res 88:293-305.

Minneman KP, Theroux TL, Hollinger S, Han C, Esbenshade TA (1994) Selectivity of agonists for cloned alpha 1-adrenergic receptor subtypes. Mol Pharmacol 46:929-936.

Mitrano DA, Schroeder JP, Smith Y, Cortright JJ, Bubula N, Vezina P, Weinshenker D (2012) $\alpha$-1 adrenergic receptors are localized on presynaptic elements in the nucleus accumbens and regulate mesolimbic dopamine transmission. Neuropsychopharmacology 37:2161-2172.

Mitrano DA, Pare JF, Smith Y, Weinshenker D (2014) D1-dopamine and $\alpha 1$-adrenergic receptors co-localize in dendrites of the rat prefrontal cortex. Neuroscience 258:90-100.

Murillo-Rodríguez E, Barciela Veras A, Barbosa Rocha N, Budde H, Machado 
S (2018) An overview of the clinical uses, pharmacology, and safety of modafinil. ACS Chem Neurosci 9:151-158.

Nakadate K, Imamura K, Watanabe Y (2001) Effects of monocular deprivation on the expression pattern of alpha- 1 and beta- 1 adrenergic receptors in the kitten visual cortex. Neurosci Res 40:155-162.

Nakane H, Shimizu N, Hori T (1994) Stress-induced norepinephrine release in the rat prefrontal cortex measured by microdialysis. Am J Physiol 267:R1559-R1566.

O’Donnell T, Hegadoren KM, Coupland NC (2004) Noradrenergic mechanisms in the pathophysiology of post-traumatic stress disorder. Neuropsychobiology 50:273-283.

Oh MM, Oliveira FA, Waters J, Disterhoft JF (2013) Altered calcium metabolism in aging CA1 hippocampal pyramidal neurons. J Neurosci 33:7905-7911.

Paspalas CD, Wang M, Arnsten AF (2013) Constellation of HCN channels and cAMP regulating proteins in dendritic spines of the primate prefrontal cortex - potential substrate for working memory deficits in schizophrenia. Cereb Cortex 23:1643-1654.

Peters A, Palay SL, Webster HD (1991) The fine structure of the nervous system: neurons and their supporting cells. New York: OUP.

Procyk E, Goldman-Rakic PS (2006) Modulation of dorsolateral prefrontal delay activity during self-organized behavior. J Neurosci 26:11313-11323.

Puumala T, Riekkinen P Sr, Sirviö J (1997) Modulation of vigilance and behavioral activation by alpha-1 adrenoceptors in the rat. Pharmacol Biochem Behav 56:705-712.

Rajbhandari AK, Baldo BA, Bakshi VP (2015) Predator stress-induced CRF release causes enduring sensitization of basolateral amygdala norepinephrine systems that promote PTSD-like startle abnormalities. J Neurosci 35:14270-14285.

Raskind MA, Peterson K, Williams T, Hoff DJ, Hart K, Holmes H, Homas D, Hill J, Daniels C, Calohan J, Millard SP, Rohde K, O'Connell J, Pritzl D, Feiszli K, Petrie EC, Gross C, Mayer CL, Freed MC, Engel C, Peskind ER (2013) A trial of prazosin for combat trauma PTSD with nightmares in active-duty soldiers returned from Iraq and Afghanistan. Am J Psychiatry 170:1003-1010.

Raskind MA, Peskind ER, Kanter ED, Petrie EC, Radant A, Thompson CE, Dobie DJ, Hoff D, Rein RJ, Straits-Tröster K, Thomas RG, McFall MM (2003) Reduction in nightmares and other PTSD symptoms in combat veterans by prazosin: a placebo-controlled study. Am J Psychiatry 160:371-373.

Ruff RL, Riechers RG 2nd, Wang XF, Piero T, Ruff SS (2012) For veterans with mild traumatic brain injury, improved posttraumatic stress disorder severity and sleep correlated with symptomatic improvement. J Rehabil Res Dev 49:1305-1320.

Seo H, Barraclough DJ, Lee D (2007) Dynamic signals related to choices and outcomes in the dorsolateral prefrontal cortex. Cereb Cortex 17:i110-i117.

Smith C, Koola MM (2016) Evidence for using doxazosin in the treatment of posttraumatic stress disorder. Psychiatr Ann 46:553-555.
Southwick SM, Krystal JH, Morgan CA, Johnson D, Nagy LM, Nicolaou A, Heninger GR, Charney DS (1993) Abnormal noradrenergic function in posttraumatic stress disorder. Arch Gen Psychiatry 50:266-274.

Southwick SM, Bremner JD, Rasmusson A, Morgan CA 3rd, Arnsten A, Charney DS (1999) Role of norepinephrine in the pathophysiology and treatment of posttraumatic stress disorder. Biol Psychiatry 46:1192-1204.

Stein MB, Kline NA, Matloff JL (2002) Adjunctive olanzapine for SSRIresistant combat-related PTSD: a double-blind, placebo-controlled study. Am J Psychiatry 159:1777-1779.

Taguchi K, Yang M, Goepel M, Michel MC (1998) Comparison of human alpha1-adrenoceptor subtype coupling to protein kinase $\mathrm{C}$ activation and related signalling pathways. Naunyn Schmiedebergs Arch Pharmacol 357:100-110.

Taylor FB, Lowe K, Thompson C, McFall MM, Peskind ER, Kanter ED, Allison N, Williams J, Martin P, Raskind MA (2006) Daytime prazosin reduces psychological distress to trauma specific cues in civilian trauma posttraumatic stress disorder. Biol Psychiatry 59:577-581.

Vijayraghavan S, Wang M, Birnbaum SG, Williams GV, Arnsten AF (2007) Inverted-U dopamine $\mathrm{D} 1$ receptor actions on prefrontal neurons engaged in working memory. Nat Neurosci 10:376-384.

Wang HX, Waterhouse BD, Gao WJ (2013a) Selective suppression of excitatory synapses on GABAergic interneurons by norepinephrine in juvenile rat prefrontal cortical microcircuitry. Neuroscience 246:312-328.

Wang M, Yang Y, Wang CJ, Gamo NJ, Jin LE, Mazer JA, Morrison JH, Wang XJ, Arnsten AF (2013b) NMDA receptors subserve working memory persistent neuronal firing in dorsolateral prefrontal cortex. Neuron 77:736-749.

Waterhouse BD, Moises HC, Woodward DJ (1981) Alpha-receptormediated facilitation of somatosensory cortical neuronal responses to excitatory synaptic inputs and iontophoretically applied acetylcholine. Neuropharmacology 20:907-920.

Wee S, Mandyam CD, Lekic DM, Koob GF (2008) Alpha 1-noradrenergic system role in increased motivation for cocaine intake in rats with prolonged access. Eur Neuropsychopharmacol 18:303-311.

Williams GV, Goldman-Rakic PS (1995) Modulation of memory fields by dopamine D1 receptors in prefrontal cortex. Nature 376:572-575.

Winder-Rhodes SE, Chamberlain SR, Idris MI, Robbins TW, Sahakian BJ, Müller U (2010) Effects of modafinil and prazosin on cognitive and physiological functions in healthy volunteers. J Psychopharmacol 24:1649-1657.

Zhang Z, Cordeiro Matos S, Jego S, Adamantidis A, Séguéla P (2013) Norepinephrine drives persistent activity in prefrontal cortex via synergistic $\alpha 1$ and $\alpha 2$ adrenoceptors. PLoS One 8:e66122.

Zhou X, Keitner GI, Qin B, Ravindran AV, Bauer M, Del Giovane C, Zhao J, Liu Y, Fang Y, Zhang Y, Xie P (2015) Atypical antipsychotic augmentation for Treatment-Resistant Depression: A systematic review and network meta-analysis. Int J Neuropsychopharmacol 18:pyv060. 